\title{
Recent development on the seismic devices for steel storage structures ${ }^{\star}$
}

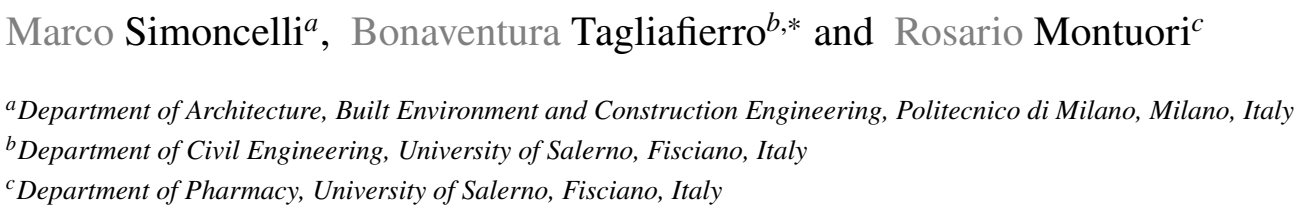

\section{ARTICLE INFO}

Keywords:

Steel storage frames

Base isolation systems

Energy dissipation devices

Thin-walled members

Dynamic response

Cold-formed members

\begin{abstract}
A B S TR ACT
Goods and products are stored in framed systems, such as pallet racks, used for industrial and commercial activities. In the last years, pallet rack code provisions for seismic loads have been significantly improved, but there are still relevant aspects that need attention for guaranteeing a safer structural design. For example, in the current European and American standards, no indications are given about the seismic isolation systems applied to these structures. Only two ways to enhance the performance of racks in seismic zones are reported: rack netting and structural strengthening. Both methodologies present logistic and technical problems. For these reasons, researchers are investigating more efficient solutions, like the base isolation systems. An accurate isolation system can bring benefits in terms of reduction of the structural damage and improving the safety of the stored items. Since the cost of the structural frame is often negligible with respect to the cost of the stored products, avoiding the overturning of merchandise is an important challenge. Moreover, sometimes falling pallets can bring to the overall global collapse due to an impact given on its beams or columns. In the paper, a critical overview of base isolation systems developed for different steel storage rack typologies is presented and discussed, highlighting the main characteristics and the advantages associated with their use in practical cases. Furthermore, four different applications of energy dissipation devices are briefly discussed, comparing these systems with the previously introduced base isolation devices.
\end{abstract}

\section{Introduction}

The skeleton frames of the industrial systems used to store goods and products represent very important and complex structures, which can be distinguished into different typologies: selective pallet racks, drive-in and drive-through racks, push back racks, gravity flow racks and rack supported platforms. As an example, in Figure 1 is reported a typical selective pallet rack with its main components. The layout of pallet racks in the down-aisle direction appears to be like the more traditional moment-resisting semi-continuous frames [1] typically employed in civil and industrial constructions. Conversely, the upright frames layout mimics the brace schemes in use for steel buildings: two - or more - columns (uprights) are laced together with diagonal and/or horizontal braces, which are frequently single-bolted on their lips. Instead of double-symmetric hot-rolled members, the cold-formed monosymmetric ones are used and the member responses can be remarkably governed by the interaction between bending and torsion [2, 3]. As it may be expected, the global response of storage steel rack systems is strongly affected by the local behaviour of both members 


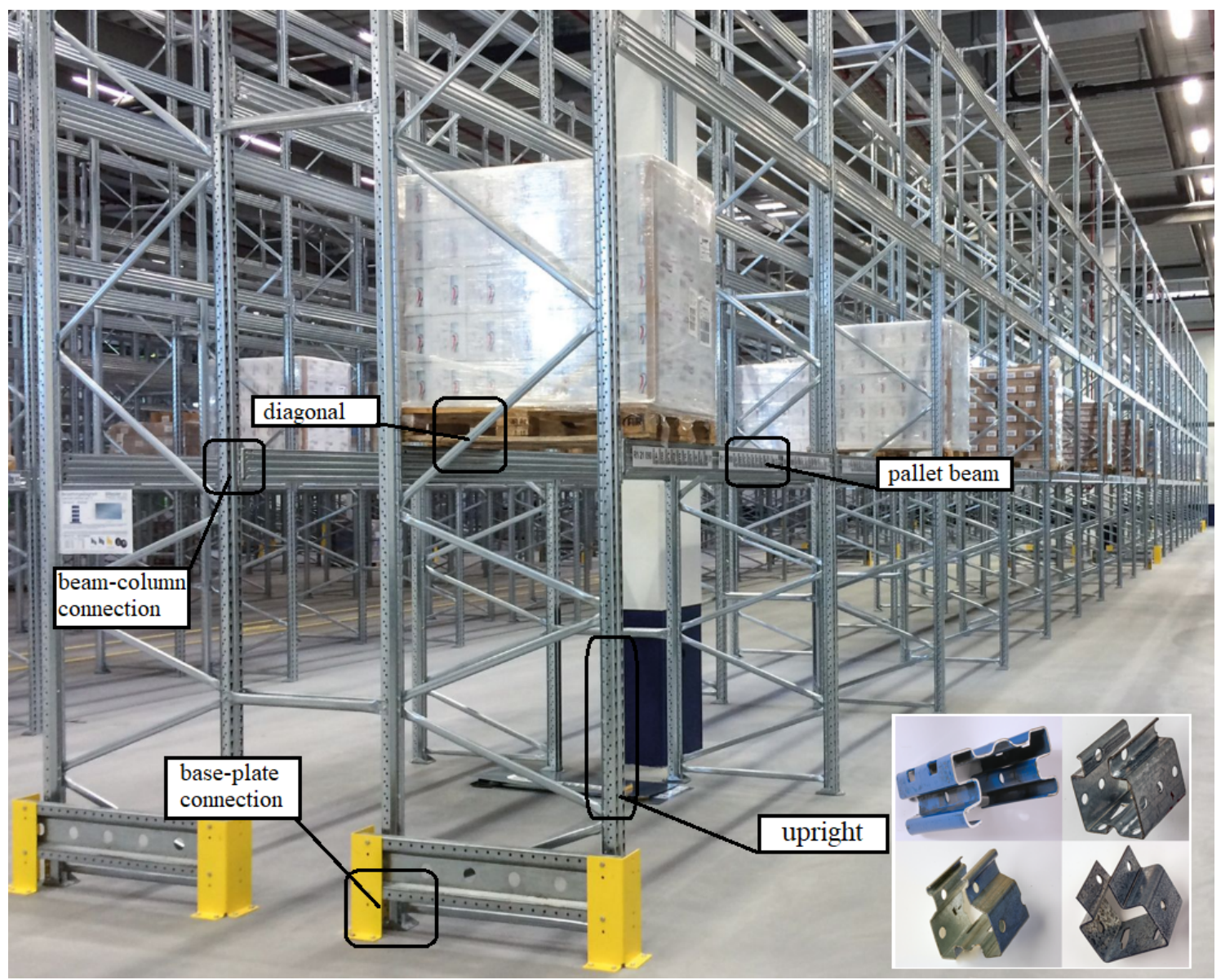

Figure 1: Typical steel storage pallet rack and its main components

and connections.

It is worth reviewing the key points to be taken into account when facing the design of racks with a seismic resistance perspective:

- Dead-to-live load. In buildings, live loads are always comparable with dead loads while, in racks, the weight of the structure is very limited - generally not greater than $5 \%$ of the weight of the pallet units. For the static design, reference must be made to [4]: along with the fully loaded rack (100\% occupancy) condition, the design can be also governed by the fully loaded rack with the exception of single unloaded bay close to the middle of the structure, at the lowest or at the second storage level. Furthermore, in the seismic design [5], together with the $100 \%$ occupancy, it must be considered also: i) the configuration with only the top storage level, used to maximise the design of anchor bolts and base-plates and ii) different occupancy levels (70\% and 50\% of the

\footnotetext{
${ }^{\star}$ This research did not receive any specific grant from funding agencies in the public, commercial, or not-for-profit sectors

*Corresponding author

@btagliafierro@gmail.com (B. Tagliafierro)

ORCID(s): 0000-0001-9171-3038 (B. Tagliafierro)
} 
total) that can generate mass eccentricities. The most relevant feature related to the load distributions is the inherent seismic masses which affect the dynamic characteristics of the structures. Contrary to what happens for buildings, the periods of vibration are greatly dependent on the considered level of occupancy, affecting hence either the seismic effects and the structural responses;

- Members cross-section. Owing to the presence of open thin-walled cross-sections, members are often prone to local and/or distortional buckling phenomena, which largely precede the attainment of the yielding capacity. Therefore, for the plastic design of such structures, it is important to rely exclusively on the post-yielding capacity of connections. On the other hand, [6] and [7] do not allow to use connection post-yielding capacity. Generally, monosymmetric profiles are employed as structural members, which lead to significant and nonnegligible torsional effects. For this reason, engineers must be able to account for the calculation of bimoment distribution along the members and the associated tangential and normal warping stresses during the design of rack frames. As discussed in [8], neglecting these effects can lead to an unsafe estimation of the load carrying capacity;

- Beam-to-column joint. Connections between horizontal elements (pallets beams) and uprights are characterised by a very limited degree of flexural stiffness and bending resistance. Pallet beam-ends are shop-welded bracket with hooks to be located on the slots of the uprights in view of quick construction of rack skeleton frames. Bolts, in addition to the hooked connection devices, could improve joint performance as proved by [9], but frequently skipped because deemed to be too expensive. Therefore, the cyclic response of standard beam-to-column rack joints is characterised by a very unstable behaviour due to a remarkable pinching of the cycles, which increases as does the level of the imposed rotation. Reference can be made to Figure 2, proposing the relationship between the non-dimensional moment $(\bar{m})$ (obtained by dividing the joint moment for the beam bending resistance) versus the relative upright-beam rotation $(\phi)$. From these curves, which are related to an experimental study [10], it can be noted that the shape of the hysteresis loops changes significantly in subsequent cycles, showing an important loss of stiffness after the first cycle [11]. However, a great issue associated with these connections is the low value of the yielding moments if compared with the ones of the connected beams. It is worth noticing that for structures as intended in [6], the connections must be designed to exhibit no plastic deformation. Great values of rotations are however achieved and, as a consequence, a satisfactory level of ductility characterises joints without brittle fracture [12];

- Base-plate joint. Also the connections between uprights and building slab are characterised by a very limited degree of flexural stiffness and bending resistance. In most of the cases, when the cross-aisle direction is considered, the seismic action can pose a risk for the overturning, which becomes the most dangerous limit state. Nevertheless, as happened for the beam-to-column connections, the nonlinear cyclic behaviour can provide a 


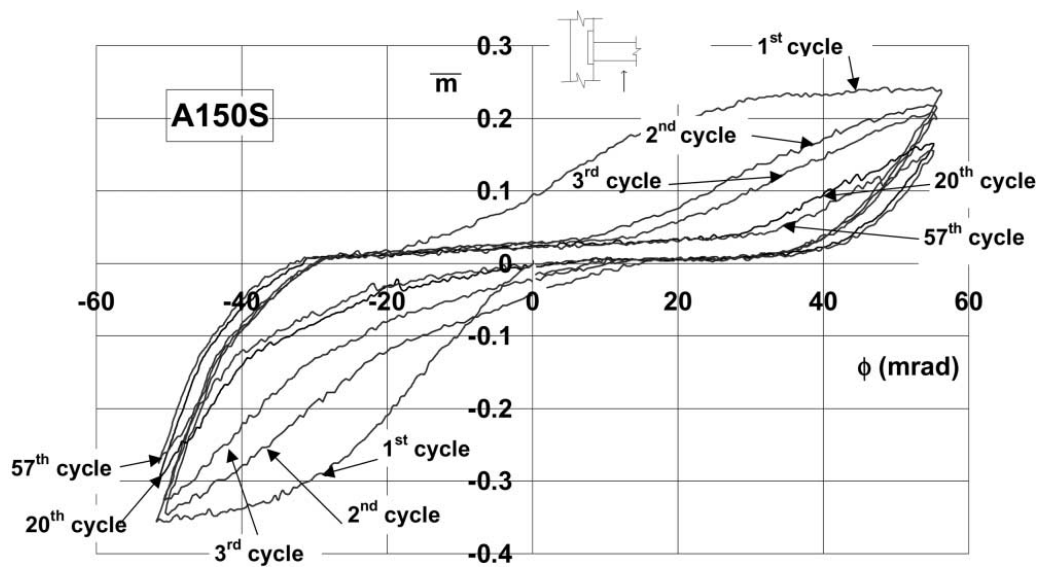

(a)

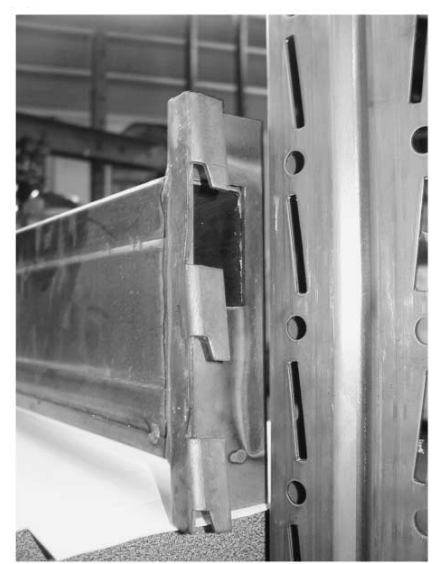

(b)

Figure 2: Examples of cyclic $\bar{m}-\phi$ relationship for beam-to-column rack joints (a), and connection details (b) [10]

non-negligible ductility to the structure. For this reason, as suggested by [5], attention must be paid on the design of base-connections to be allowed to use a behaviour factor $q$ grater than 1 (but however lower than 2) in the seismic structural analysis;

- Dynamic response. The seismic response of the two principal directions is rather different. In the down-aisle direction, the great flexibility provided by connections and the absence of spine bracings reflect in significantly high value of the fundamental period of vibrations $(\mathrm{T})$, sometimes up to $3.50 \mathrm{~s}$, which are the typical values observed for high-rise and tall steel buildings.Conversely, in the cross-aisle direction, the presence of bracing systems ensures a fundamental period lower than 1.50s. Despite their conventional lateral resisting schemes, seismic performance along the transverse direction is utterly dictated by base connections and brace-to-upright connections [13], where the inelastic deformations take place [14].

As it appears clear by considering the previous discussed points, it is a quite complex task to predict the rack's behaviour. High engineering competences are required to accurately reproduce the key features of each item and hence to attain the global frame response guaranteeing, at the same time, competitive performance with structural systems of extremely limited weight (cost). As discussed, racks are frames made up of members hardly able to dissipate energy, but however able to sustain significant lateral displacements owing to the high level of rotation that can be reached in post-elastic range by joints. This behaviour has been confirmed also recently by pushover analyses on shelving racks [15] and pallet racks [16].

Rack design standards have been recently updated worldwide: in Europe [4, 5, 17] ;in Australia [18] ;in the US $[19,20]$. Many recent analyses that can be found in [21] and [22], which respectively focus on industrial structures in Christchurch after the 2010 Darfield earthquake and damage to non-structural elements during 2016 Central Italy earthquake, have indeed underlined the need for safer ways of design racks against seismic effects. It was recognised 
that the poor performance of rack structures was mainly due to lacking of details for bearing lateral forces [23]. It is also recognised the high fragility of the cross-aisle frames which often experience column bucking failures [24] and ground anchoring failures [25]. The framework established by the latest code provisions identifies the performance criteria that racks must comply with. Along with No Collapse and Damage Limitation requirements, it is mandatory to consider the Movement of the Unit-Load due to seismic-induced accelerations. Pallet sliding, albeit favourable, may lead to shed of the contents and, in the worst scenario, to the unseating of the unit-loads. This is of particular concern when the area where goods are stored is publicly accessible henceforth being falling goods a human-life hazard. Besides, classical procedures which mainly deal with strengthening and stiffening structures cannot increase the safety of warehouses against the shedding of goods, which is recognised as a performance level. Rather, it is necessary to reduce floor accelerations to be effective on the movement of the stored items. For instance, to avoid shedding of goods, [20] suggests several restraint practices depending on the way the merchandise is stored.

Regarding the structural analysis, ref. [5] proposes the classical four different methods suggested also by [26] for common structures: Lateral force method (LFM), Modal response spectrum analysis (MRSA), Pushover analysis (POA) and Nonlinear time-history analysis (NLTH). The only requirement to choose one over another is to check the inter-storey drift value, which is directly related to the importance of the second order effects. Actually, [5] states that the MRSA is the reference method to be used for adjustable pallet racking systems under seismic forces. Despite in the recent years the evolution of the computer capabilities of performing complex computations, engineers, in the practical cases, prefer to perform linear analyses (LFM or MRSA method) considering a behaviour factor $(q)$, in general, equal to 1.5 or 2.0 (without any deep investigation, as admitted by [5]). In the Author's opinion, the NLTH is the method to be used, because it is the only one able to take into account all the peculiarities of these structures. The two paper Bernuzzi et al. [11,27] propose a mixed procedure combining the NLTH with the low-cyclic fatigue theory approach, which has been developed and applied to rack frames. The low-cyclic fatigue theory has been added to the NLTH in order to monitor, during a seismic event, the damage state in beam-to-column and base-plate connections. This methodology can be easily applied and take into account the rack peculiarities giving important design information to the designers.

In the following, after a brief recall on the main principles of base isolation systems, the paper presents a critical overview of the seismic devices developed for different steel storage rack typologies, highlighting the main features and the advantages associated with their use in practical cases. In addition, different applications of energy dissipation devices are briefly discussed. As previously discussed, in the current European and American standards no indications are given about the seismic isolation systems applied to racks. In the Authors' opinion, it is important to spread awareness among researchers that not only the 'classical' design is allowed for these frames, but also isolation systems can be adopted. 


\section{Suitability of traditional design methods for earthquake-resistant structures for steel}

\section{storage structures}

Presently, the common practice for the seismic design of buildings tends toward safeguarding the human life by assuring an adequate level of reliability after the seismic events and guarantees the capability of structures to be rehabilitated after a seismic event $[28,29]$. The Seismic design objective is to prevent the collapse of buildings—accepting the occurrence of extensive damage - relying on ductile resources. Of course, in order to maximise the exploitation of local ductility, structures have to be globally guided to exhibit a global collapse mechanism [30, 31]. To accomplish this, however, elements must be thoroughly sized to guarantee the failure-control approach, which acts through the capacity design principles [32]. The regions where structures have to exhibit plastic deformations are identified and therefore designed with reliable strengths, whereas the brittle-prone regions are designed with hierarchically imposed strengths.

Damage is a consequence of plastic deformations that are unavoidable — desired — to dissipate earthquake energy, as long as current seismic code design procedures are to be fulfilled. For what concerns steel structures, members made up of compact hot-rolled laminated profiles possess high ductility inherently, hence allowing for plastic design of structures. On the other hand, the knowledge transfer to rack structures is hardly straightforward. In the first place, low plastic members' resources do not allow to rely on such to provide structures with enough post-elastic deformations. The connections are hence identified as the place where plastic deformations can happen - this indeed goes towards the capacity design principles, though tabs and slits do not assure ample and stable hysteretic cycles. In fact, beamto-column and base connections inherit their geometries from static load design procedures and have not been yet updated to the demand for more ductility. Secondly, the common practice to have the same upright cross-sections along the elevation constrains the designers' choices, making hierarchy criteria not so plainly enforceable for manifest economical feasibility.

Therefore, it is necessary a non-conventional way to design these structures and base isolation system seems to be an adequate solution.

\subsection{Main principles of base isolation system design}

Since the first insight about the seismic isolation of buildings, the know-how available has faced a trial-and-error update procedure, which nowadays results in a great variety of devices and related techniques to be used for the seismic isolation of infrastructures and buildings [33]. Over more than a century of developments, seismic isolation seems presently to be a mature solution for a new approach to earthquake-resistant design of structure [34], which can ensure post-earthquake functionalities [35]. When the problem concerns buildings, base isolation system (BIS) is the most convenient and effectively capable of mitigating earthquake effects [36]. In general, BIS introduces a layer between structures and foundations (or basements) made up of suitable devices with low lateral stiffness, which however 
preserve the former vertical stiffness. The insertion of the isolation system allows to set the fundamental period of vibration of the structure at will, which may be selected to be decoupled from the energy contents of most the expected seismic events.

As it is well established, the kinematics of a seismically isolated building can be studied assuming a model with 2 degrees of freedom (2DOF), after the linear theory of [37,38]. Figure 3 depicts the linear elastic 2DOF model with lumped masses, which may be considered a synthesis of base isolated structures. In terms of relative displacements, which are convenient to compare both super-structure displacement $u_{s}$ and base displacement $u_{b}$, the equations of motion are given by:

$$
m_{s}\left(\ddot{u}_{b}+\ddot{u}_{s}\right)+c_{s} \dot{u}_{s}+k_{s} u_{s}=-m \ddot{u_{g}}
$$

$$
\left(m_{s}+m_{b}\right) \ddot{u_{b}}+m \ddot{u_{s}}+c_{b} \dot{u}_{b}+k_{b} u_{b}=-\left(m_{s}+m_{b}\right) \ddot{u_{g}}
$$

where $m$ is the mass, $c$ is the damping coefficient, $k$ is the stiffness, subscripts $b$ and $s$ refer to isolation system and super-structure, respectively. $\ddot{u_{g}}$ is the ground acceleration. Equation (1) is characterised by a circular frequency $\omega_{s}^{2}=k_{s} / m_{s}$ that is related to the main structure (fixed structure), whereas Equation (2) by $\omega_{b}^{2}=k_{b} /\left(m_{s}+m_{b}\right)$, which is related to the isolation system. It is useful to define the ratio between the periods of the systems $\epsilon=\left(T_{s} / T_{b}\right)^{2}$. The solution of the eigen-problem associated to the system on equation (1) and (2) yields to identify the two modal periods,

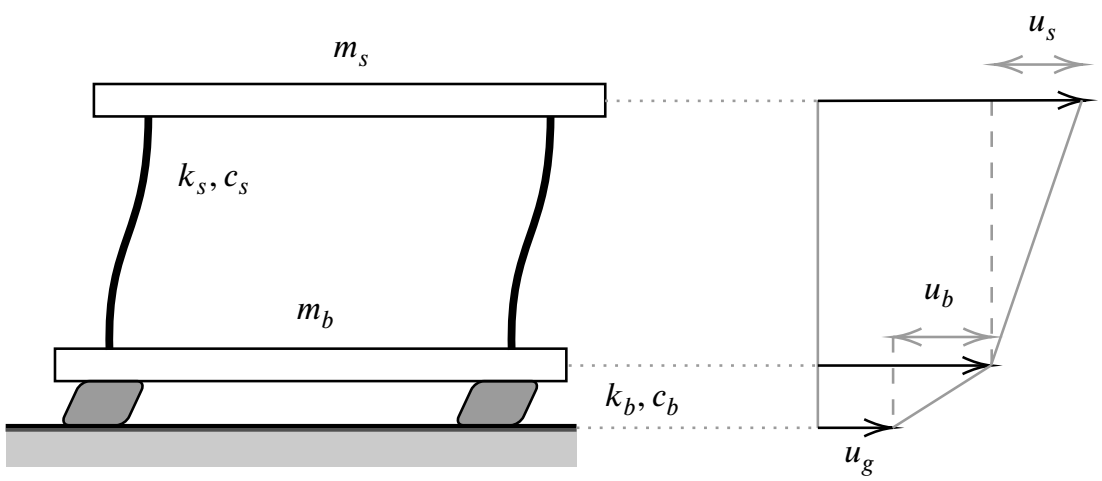

Figure 3: 2DOF base isolation system mechanical model, after De Luca et al. [33] 
approximated to the first order of $\epsilon$ :

$$
T_{1}=T_{b} \sqrt{1-\gamma \epsilon}, \quad T_{2}=T_{s} \sqrt{\frac{1+\gamma \epsilon}{1-\gamma}}
$$

where $\gamma=m_{s} /\left(m_{s}+m_{b}\right)$.

As long as the first order approximation of $\epsilon$ holds, the first period of vibration $T_{1}$ is almost the same of the isolation system $T_{b}$, while the structural period is increased and this effect is as strong as the value of $\gamma$ increases. This also reflects on the structural damping of the system. The damping ratio of the first mode yields to:

$$
\xi_{1}=\xi_{b}\left(1-\frac{3 \gamma \epsilon}{2}\right)
$$

Equation 4 leads to a damping ratio quite similar to the damping ratio that characterises the dynamic of the isolation system. Additionally, another benefit comes from the participation factor associated to the first mode, which happens to be $\Gamma_{1}=1-\gamma \epsilon$, ensuring that most of the seismic effects set into action the structure with a favourable deformed shape [39]. It can be instructive to consider the first mode shape $\phi_{1}=[1, \epsilon]$, which clearly states, though the structures undergoes deformation, the most of the displacement is gathered at the isolation level.

This heads to the following beneficial effects if compared to buildings without seismic isolation:

1. the significant reduction of the accelerations transmitted to the super-structure, even at the higher levels;

2. the reduction of the inter-storey drifts: in simple terms, under the action of the earthquake the building moves as a rigid block above the isolators.

\subsection{Seismic isolation for steel storage systems}

These aspects, if applied to rack systems, are beneficial because of it is possible to avoid the overturning of the stored goods, that is a typical problem when an earthquake income on these structures, as shown in Figure 4, the downtime of structures is extraordinarily cut down after seismic events.

Although a huge number of seismic devices are nowadays available on the market $[36,41,42]$, it may be complicated to apply them directly to rack systems because of economic and technical reasons:

- for a proper installation of the base isolation system, a rigid diaphragm must be created to avoid differential displacements between uprights. This can raise a logistic issue because also the pallet slots at ground level must be completely free for the storage of heavier pallets. Moreover, owners avoid using bracing in the down-aisle direction as well;

- the loads applied to the racks can change day by day and very different value of the axial load in the uprights can be found. Only logistic reasons govern the load-unload phases and no attention are given to the structural 

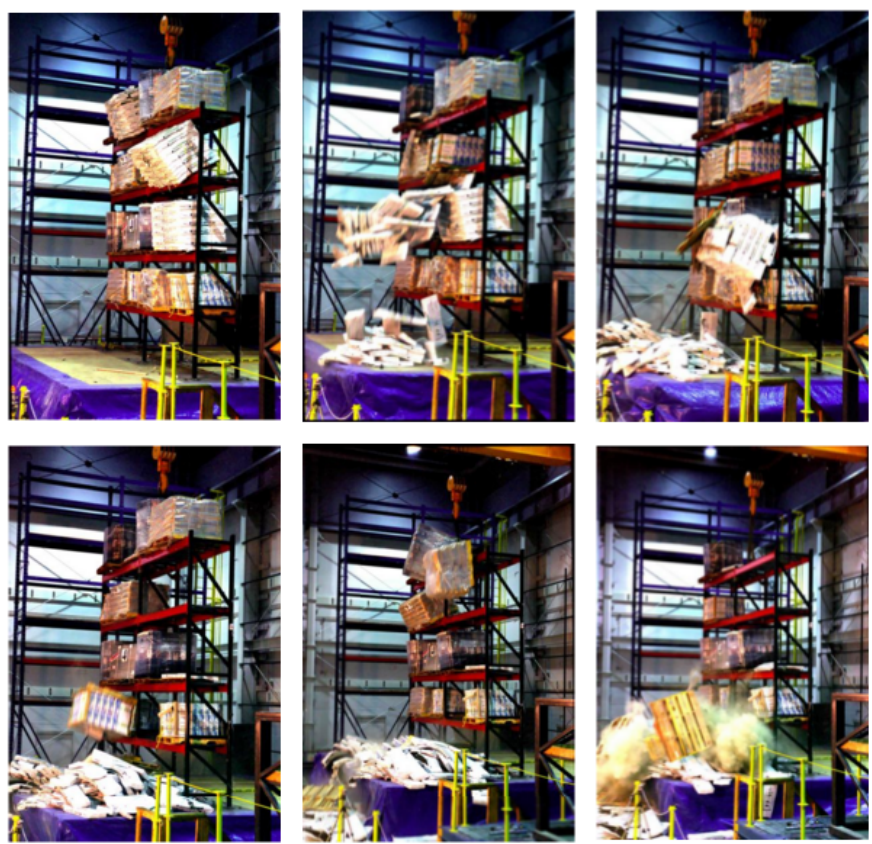

Figure 4: Shake table tests on non-isolated steel storage pallet racks [40]

condition. In many cases, great mass eccentricity is created and consequently torsion effect becomes predominant. Mass variability may represent an issue for some kind of base isolation system, which provides different periods depending on the vertical loads, e.g. the ones made with rubber;

- the lateral resisting system is characterised by high slenderness. The limited plan dimension and the great height of the racks can bring to the base-uplift problem along the cross-aisle direction, which could be a problem for the isolator hardware. Most of the seismic devices are not able to bear tension (sliding devices) or cannot work properly (rubber bearing systems). A purposely developed hardware may be considered [43], which is capable of bearing compression as well as tension;

- the dimension of rack uprights is very small if compared with the columns of the traditional building or with the bridge piles, where usually the isolators are located. Also, the vertical loads are one or even two order of magnitude less than the usual ones, which are necessary for a certain class of isolators to work efficiently. It is worth referring to the period of vibration of a rubber isolator device, which can be roughly estimated as:

$$
T_{d e v} \approx 2 \pi \sqrt{\frac{\sigma}{G} \frac{n t_{r}}{g}}
$$

where $\sigma$ is the vertical stress, $G$ is the rubber shear modulus, $t_{r}$ is the thickness of the rubber layers, $n$ is the number of rubber layers, $g$ is the magnitude of the acceleration of gravity. Equation (5) underlines the reason rubber devices cannot apply for the isolation of a system with low mass. The quantities $G$ and $n t_{r}$, though may 
be changed, are constrained by technological issues and displacement demand, respectively. Hence, the vertical stress upon device imposes the period of vibration, which increases with $\sigma^{1 / 2}$. For instance, considering soft rubber and a shear strain $\gamma=150 \%$, reasonable figures are $G=0.70 M P a, n t_{r}=0.15 \mathrm{~m}$ and $\sigma=7.00 M P a$ lead to $T d e v=2.46 \mathrm{~s}$. However, for pallet racks, it is hard to exceed $\sigma=1.00 \mathrm{MPa}$, so that the corresponding period through Equation (5) yields to around $0.92 s$. The reader, who is interested in more detail about the procedure and the values employed herein, can find examples in [33, 37]. Equation (5) can be found also in the Design Recommendations for Seismically Isolated Buildings by Architectural Institute of Japan;

- the direct cost of a common base isolation system has a major impact on the cost of the storage rack frames alone. Moreover, throughout the rack life, the owner of the warehouse can change as well as the ownership of the stored goods [44]. Often, owners prefer to charge on themselves the risk of a possible collapse rather than investing more money in engineer costs, especially when the costs of the merchandise are not so relevant.

For these reasons researchers are nowadays studying and trying to develop innovative and more efficient devices. 


\section{Principal applications of base isolation strategy on steel racks}

\subsection{Warehouse and high-rack structures}

Important studies on high-rack structures with base isolation systems have been carried out by Kilar et al. [45, 46] were the nonlinear responses of the Fixed Base (FB) and Base Isolated (BI) high racks, with various mass eccentricities, were analysed by using either nonlinear dynamic time history analyses (NLTH) and pushover analyses (POA). The presented case study is relative to a real application and its structural model is depicted in Figure 5. The uprights of the rack structure are made of omega 100x120mm (outer dimensions) cold-formed sections ( $H$ in Figure 5), forming the upright frames by means the use of diagonals realised with C 50x30x3mm profiles ( $\mathrm{K}$ in Figure 5). Uprights have been perforate only where beams have been located. Lateral stability have been increased by means the use of supporting bracing towers located at both end of the structure. The columns of the supporting structures are made of hot-rolled HEA200 (A in Figure 5) sections. All the beams are made of welded boxed SHS type profiles (B,C,I in Figure 5), and the diagonals are double $\mathrm{L}$ sections (D,G,J in Figure 5). The internal sides of the supporting structures are additionally braced by double L sections (E in Figure 5). On the top beams are made of HEA100 (F in Figure 5) profiles while top bracing are UPN120/55 (L in Figure 5). The supporting systems provide an increased rigidity to the racks structure compared to the classical unbraced racks frame.

The base isolation system was designed in order to ensure that no damage occurs in the fully and symmetrically loaded rack structure after an earthquake. The isolation system was composed by rubber bearings with a diameter of $45 \mathrm{~cm}$ and a total height of $24 \mathrm{~cm}$ (including outer steel plates) [47]. They were made of soft rubber (40 durometer) and

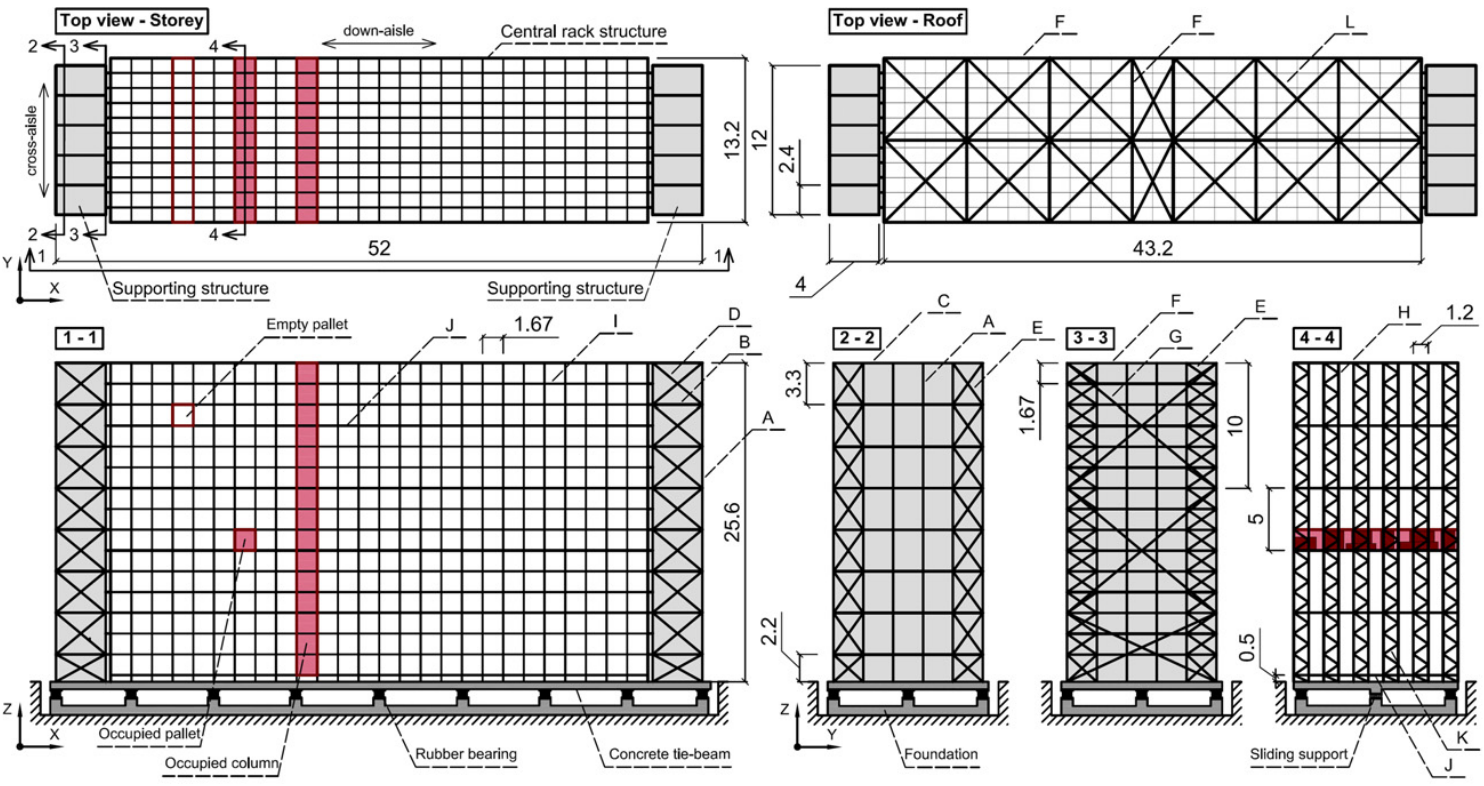

Figure 5: Geometry of the base-isolated rack structure with its two outer supporting structures (dimensions in metres) [45]. 
have a horizontal stiffness of $650 \mathrm{kN} / \mathrm{m}$, with a damping ratio equal to $\xi=0.10$. Their maximum allowed horizontal displacement is equal to $200 \mathrm{~mm}$ and the maximum admitted vertical load is $900 \mathrm{kN}$ under seismic actions and 3570 $\mathrm{kN}$ for static load case. A set of 20 rubber bearings, which are distributed around the perimeter of the structure layout, have been designed, whereas the middle points of the plan layout are vertically supported by flat-sliding devices. To ensure a uniform distribution of stresses and to create a rigid plan onto the base isolation system, a reinforced concrete slab with $30 \mathrm{~cm}$ of thickness and a series of concrete tie-beams $(\mathrm{b} / \mathrm{h}=40 / 60 \mathrm{~cm})$, forming a $6 \mathrm{~m} \times 6 \mathrm{~m}$ grid, was added beneath the structure. This stiff diaphragm resulted in 633 tons of additional mass at the base-storey. The centre of stiffness of the isolation system corresponds to the centre of stiffness of the superstructure [45], as well as to the geometrical centre of the floor plan.

The structure was modelled and analysed by using the commercial finite element (FE) computer software SAP2000 v12.0.1 [48], which is reliable to perform nonlinear dynamic analyses. Firstly, second-order modal analyses have been performed to obtain the fundamental period $T_{1}$ of both models. FB rack has shown a fundamental period of $1.35 \mathrm{~s}$ in the down-aisle and $1.25 \mathrm{~s}$ in the cross-aisle direction. As expected the base isolation system has increased those values: $3.47 s$ and $3.42 s$ in the down- and cross-aisle directions, respectively. It must be underlined that these preliminary analyses were performed considering the fully loaded loading condition. After, a parametric study has been carried out by varying the mass eccentricity in both FB and BI models and two different peak ground accelerations $\left(a_{g}\right)$ have been selected, namely $0.175 g$ and $0.250 g$.

The structure sensitivity to asymmetric live load distributions was analysed with respect to the inherent eccentricity $e_{\max }$, which represents the distance between the centre of mass and the geometrical centre of the structure. A final summary of the most important outcomes of the analyses carried out in [45] are reported in Figure 6. Sub-figure 6(a) reports, for each relative eccentricity $e_{\max } / B$ ( $B$ is the total length of the structure), the relative displacements of the frames on either the stiff and the flexible side, and the centre of mass (CM). Similarly, sub-figure 6(a) reports the storey drifts for the rack structure (left panel) and the supporting structure (right panel).

From the 4 panels in Figure 6, it can be noted that for the FB rack structure the most critical occupancy is not the fully one $\left(100 \% \rightarrow e_{\max }=0 \%\right)$, but rather occupancy levels ranging between $85 \%$ and $55 \%$, which can produce maximum eccentricities ranging from $5 \%$ to $15 \%$ of the larger floor plan dimension. Incidentally, it must be noticed that also a different structural period can vary the effects of the ground motion on to the super-structure. For the FB structure, the plastic hinges develop either at column-ends and diagonals of the supporting structures and at the base of columns on the flexible side of the central rack structure, which may lead to a dangerous local collapse mechanism. The accidental eccentricity, which is prescribed by Eurocode8 (5\% of the floor plan dimension), might be too small to correctly account for an unfavourable asymmetric payload distribution. On the other hand, the introduction of the base isolation system does flatten the effects of having different occupancy levels, as it can be observed from the 4 panels in Figure 6. In fact, the relative displacements as well as the storey drift are hardly affected by eccentricity. Additionally, 
the system can significantly reduce the unfavourable effects of torsion.

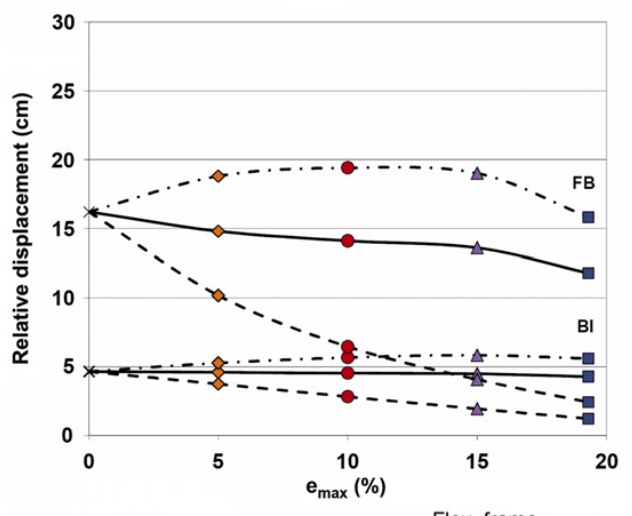

(b) $\mathrm{a}_{\mathrm{g}}=\mathbf{0 . 2 5 \mathrm { g }}$

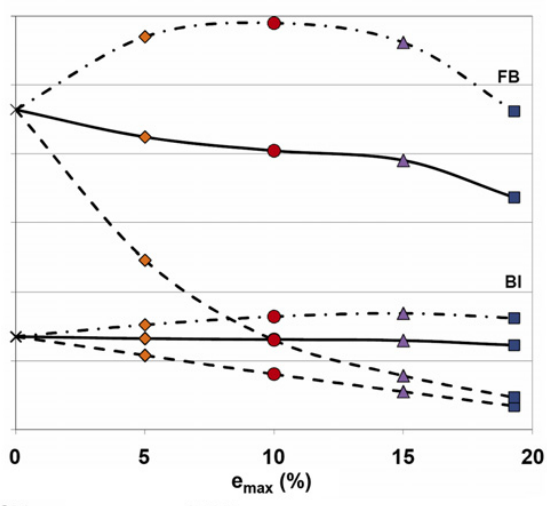

- - Stiff frame

(a)
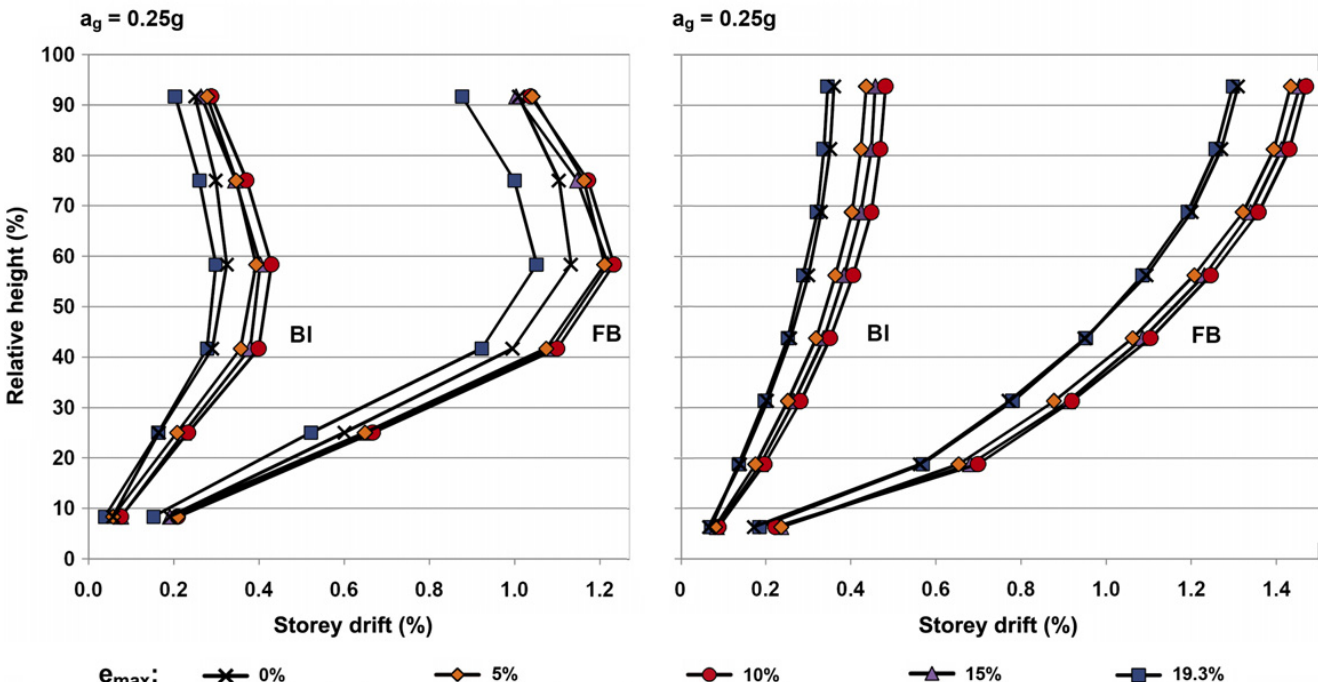

(b)

Figure 6: Deck rotation of the models for different mass eccentricities (a) and storey drifts of the models for different mass eccentricities (b) [45].

As a whole, the effects of torsion in the BI structure are smaller than the ones in the FB structure: the reduction in torsional deck rotations was by a factor of 5 (Figure 6(a)). Furthermore, the reduction in terms of inter-storey drifts was by a factor of 3 as can be observed from Figure 6(b). Overall, the implementation of a BIS can therefore be a very effective solution, since it can get rid of all damages from the rack structures as well as from the supporting structures.

Finally, Kilar et al. [46] presents an interesting cost analysis on the same high rack structure of Figure 5. Figure 7 reports the data of a cost analysis performed on 2 configurations (i.e. SYM and ASYM, short for symmetric and asymmetric, respectively) of the same structure and with 2 seismic intensities. The difference between the two 
cases stands in the way the pay-load is distributed i.e. SYM $e_{\max }=0 \%$; ASYM $e_{\max }=10 \%$. However, both of them share the same occupancy level. It was shown that a base isolation system is probably not economically feasible for smaller to moderate ground motion intensities, if only the pure repair costs are observed. However, if the downtime ( $C_{d}$ loss of function) costs and damaged content costs are taken into consideration, along with the structural costs $C_{s}$ and the damaged content costs $C_{c}$, it can be noted that the isolation system could be economically viable for all the analysed seismic intensity (Figure 7). The costs of base isolation are represented by the red straight line, and can be approximated to $10 \%$ of initial building costs. If the total costs are considered, it can be noted that the costs increase as the seismic magnitude does and if full occupancy is considered, the total induced costs could exceed the costs of the original structure. The base isolation solution results always the more convenient. Obviously, the results of this cost analysis are strictly dependent on the Authors' assumptions on the costs and on the duration of different structural recovery operations. The Authors of this work have found that those assumptions are fairly representative of a real-like scenario.

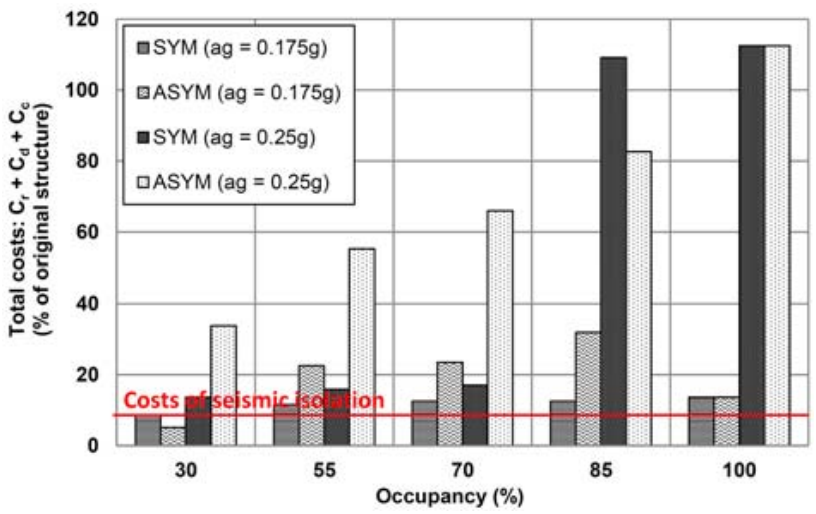

Figure 7: Seismic isolation costs versus total costs (structural repair, downtime and damaged content) for different occupancy levels and ground motion intensities [46].

It can be concluded that the discussed isolation strategy can be classified as a classical base isolation procedure, commonly used for buildings, and grounds on a well-know theoretical background. Both articles [45, 46] present an interesting application of a base isolation system to a non-conventional structures, which requested to develop a more extensive analysis campaign for the high uncertainties related to the mass distribution. Since the isolation system is made up of elastomeric seismic isolators, the great variability of the mass distribution does affect the fundamental structural period which, in turn, implies different seismic effects on the super-structure. In contrast, the seismic isolation of buildings has much fewer degrees of freedom. Nevertheless, a great advantage arises, that is, the main peculiarities of racks systems can be partially faced and the suppliers of such structures could use their long-established know-how also for seismic-prone areas. 


\subsection{Wine-barrel racks}

Losses experienced by the wine industries after severe quake events have underlined the structural weakness of the winery facilities $[49,50]$. Most of the spilled wine was stored in steel legged tanks, which experience local buckling failures of the tank walls [51]. However, high quality wines and spirits are often stored in wooden wine barrels, whose racking systems also have undergone several collapses. On the wake of this, the work of Candia et al. [52] investigated analytically the behaviour of wine barrel configurations, identifying a remarkable increase of forces in the stack's components. Some published research was focused on the nonlinear rocking behaviour of wine barrel stacks during seismic excitation. Chadwell et al. $[53,54]$ conducted a research to provide wine barrel stacks with collapse mitigation by using seismic isolation ball bearings.

The system proposed by [54] is a bearing device which leans on balls made of hardened steel, rolling inside a polished cubic polynomial surface (Figure 8(a)). The best curved surface was fit through computer simulations to optimise the transference of forces from high frequency earthquake vibrations by minimising the initial bearing stiffness anywhere - flat surface. Moreover, for near source type ground motions containing either fling steps or velocity pulse type characteristics, the design was such that the ball bearing force transmittance was limited. This was accomplished when the ball bearings, rolling upon a curved surface, reaches the critical friction angle where the ball slides against the surface while continuing to roll upon the concrete warehouse floor. Figure 8(b) depicts the hysteretic behaviour of the device highlighting the three main phases. In this application attention is paid only on collapse prevention and excessive lateral displacements are not a main concern.

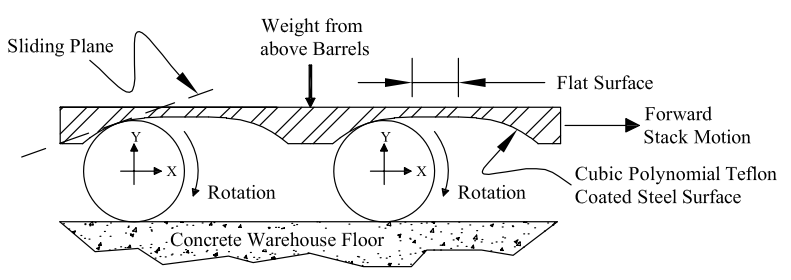

(a)

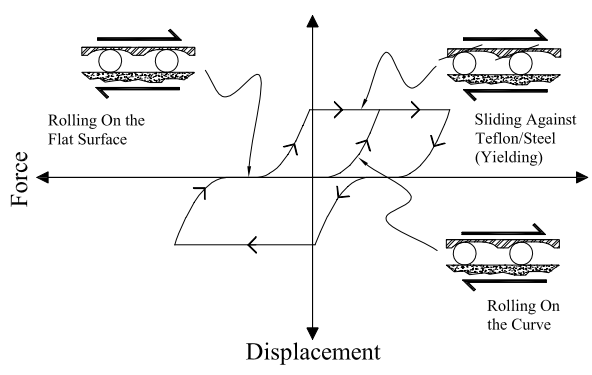

(b)

Figure 8: Isolation device schematic (a) and force-displacement articulation model of the isolation device (b) [54]

The proposed base isolation system allows for unrestrained lateral displacements of the whole barrel stack relative to the concrete floor. If the friction coefficient at the base of the system is reduced, the effective base shear capacity and associated force transmission to the barrel stack are proportionately reduced. The sliding demand-to-capacity ratio of the bottom barrel level at the location of the isolation bearings becomes the controlling failure mechanism. Analyses show that a friction coefficient of approximately $16 \%$ and below would provide seismic protection for a four-level barrel stack. The behaviour of the bearing (Figure $8(\mathrm{~b})$ ) is such that as the ground moves underneath the device due to 


\subsection{Pellegrino ${ }^{\circledast}$ isolation system}

The isolation system developed by RIGID-U-RAK [https://www.ridgurak.com/accessed 2020] have been named with the trademark Pellegrino ${ }^{\circledR}$ and provides seismic isolation exclusively in the cross-aisle direction of pallet type steel storage racks, by incorporating high damped elastomeric bearings and friction plates (Figure 10(a)). Filiais cubic, the resulting force-displacement curve is roughly parabolic and the tangent stiffness consequently changes linearly with increasing lateral displacements. As the hardened steel ball bearing rolls up the curve, the force tangent to the ball bearing surface reaches a capacity that is dictated by the friction coefficient between the two surfaces.

Once this capacity is reached, the ball slides against the Teflon surface, essentially creating an equivalent yield force (force transmission fuse). While at this yield point, the bearing will no longer travel along the cubic surface but will continue to travel on the ground below, increasing displacement, while transmitting a limited force up through the stack equal to the friction coefficient times the weight above. Unique to this type of system is that the horizontal yield force is the same as the friction force tangent to the contact of the bearing with the surface. Furthermore, the reaction at the concrete ball bearing contact point is equal to the normal force at the surface/ball bearing contact point. However, the ball bearings leave a small pock mark on the concrete floor slab, introducing a force that must be overcome before the stack can move. With the chosen surface and a dimension of $19 \mathrm{~mm}$ diameter for the ball bearings, the numbers of contact points was 16 . The isolation system was created for a maximum of five-barrel stack with $28 \mathrm{kN}$ of weight.

The Authors have conducted also some interesting experimental activities on shake table with different input ground motions (named LA16, LA18 and LA19). In Figure 9 the results obtained from the last ground motion, whose peak ground acceleration was around $0.70 \mathrm{~g}$, are sketched. After the tests, the Authors report that the total relative displacements were concentrated between the base rack and the simulated concrete floor. No rocking of barrel was observed. It can be noted that little residual displacements remain after earthquake, highlighting no fully re-centring capacity of this isolation system. Nevertheless, this problem was not addressed by the Authors at all.

The evidence from initial full scale testing of wine barrel stacks mounted upon an isolation system consisting of a steel ball bearing rolling/sliding in a concave cubic polynomial surface is promising. The device has shown to be working as designed for the wine barrel configurations tested and to mitigate wine barrel stack collapse by effectively decoupling the wine barrel stack from the ground motion. Unluckily, no comparison is made between isolated and nonisolated system so the improvement given by the isolation system is not clear. This research program will conclude with a statistical analysis to establish the probability of failure of wine barrel stacks as both a function of stack height,

The reported results clearly show the efficiency of this isolation system, which is able to mitigate the acceleration and avoid the overturning of the wine-barrels. This system can be easily adopted also in different rack systems. Unfortunately, no information about cost-analysis is reported.

seismic excitation, the ball is forced to roll against the surface like a pendulum system. However, because the surface 


\section{One Level Stack}

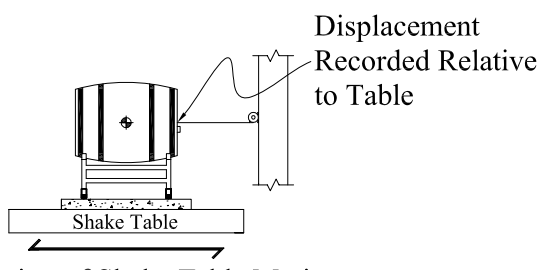

Direction of Shake Table Motion

\section{Two Level Stack}

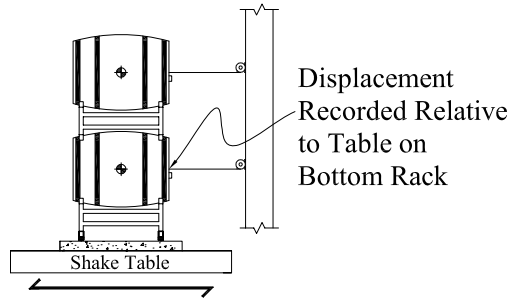

Direction of Shake Table Motion

(a)

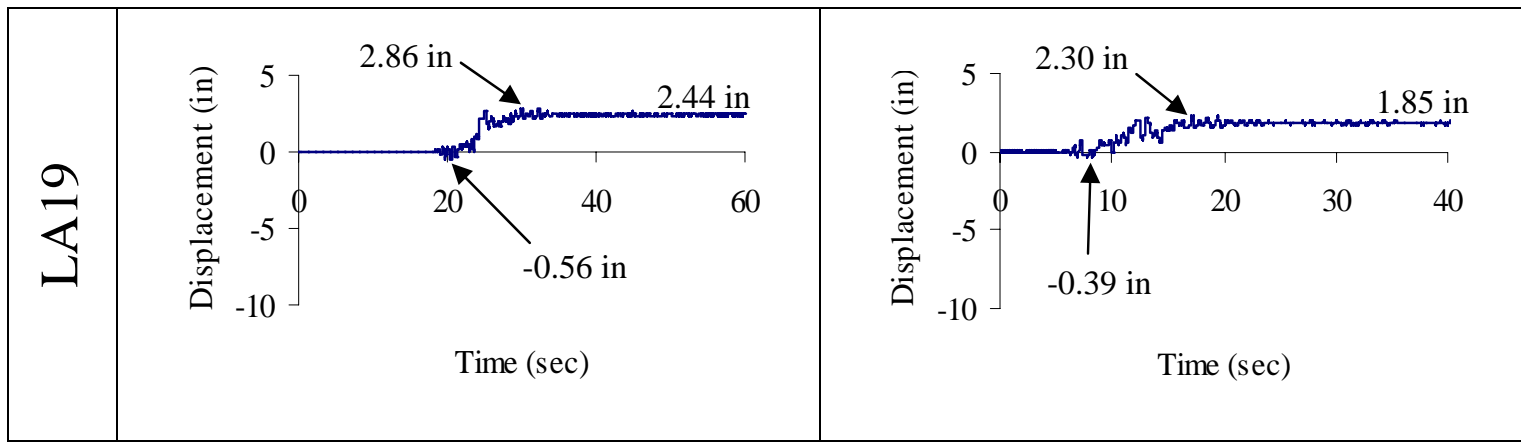

(b)

Figure 9: Considered structures (a) and their seismic responses under the North Palm Springs, 1986 (LA19) (b)[54]

trault et al. [40] presents a summary of experimental results from tests of isolated pallet racks performed on the triaxial shake table at the University of Buffalo (US). The base isolation system considered in this study is designed to provide base isolation in the cross-aisle direction of a pallet rack system, while providing similar restraints as conventional bolted base plates in the down-aisle direction.

The objective of the isolation in the cross-aisle direction is to reduce the horizontal accelerations of the rack in order to avoid content spillage and structural damage during a major seismic event, without interfering with normal material handling operations. The base isolation is not designed to provide isolation in the down-aisle direction, though. The system (Figure 10(b)) consists of a U-shape plate (Horizontal Support), inserted inside a steel box (Box Fabrication) which is welded on the base plate (Base Plate). Actually, the base plate and the steel box make up a one-piece component, which represents the fixed part of the device (refer to Figure 10(a)). As it may sound clear, the base plate is anchored to the building slab by means of anchor bolts. In this framework, the two uprights are bolted onto the flange of the U-shape profile. Two seismic mounts make up the connection between the movable part, i.e. the horizontal support plate, and the fixed one, i.e. box fabrication + base plate.

The lateral seismic shear forces are carried by the mounts and by friction between the horizontal support and 


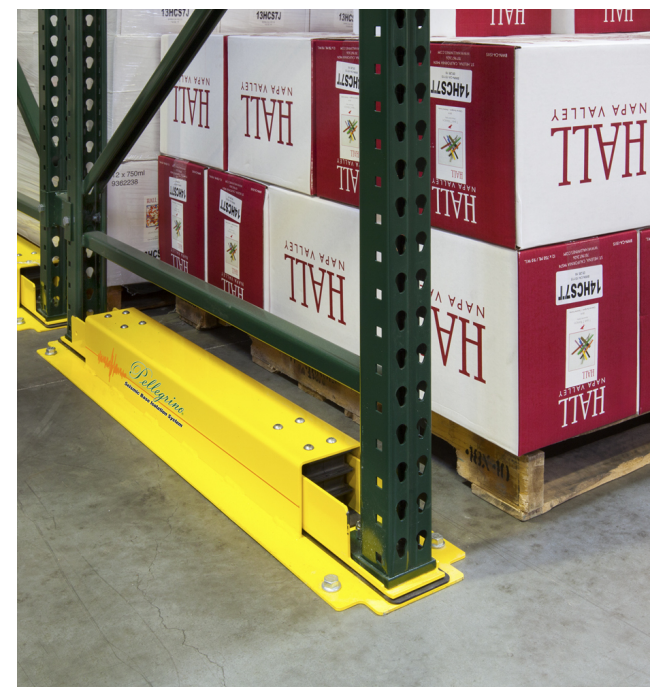

(a)

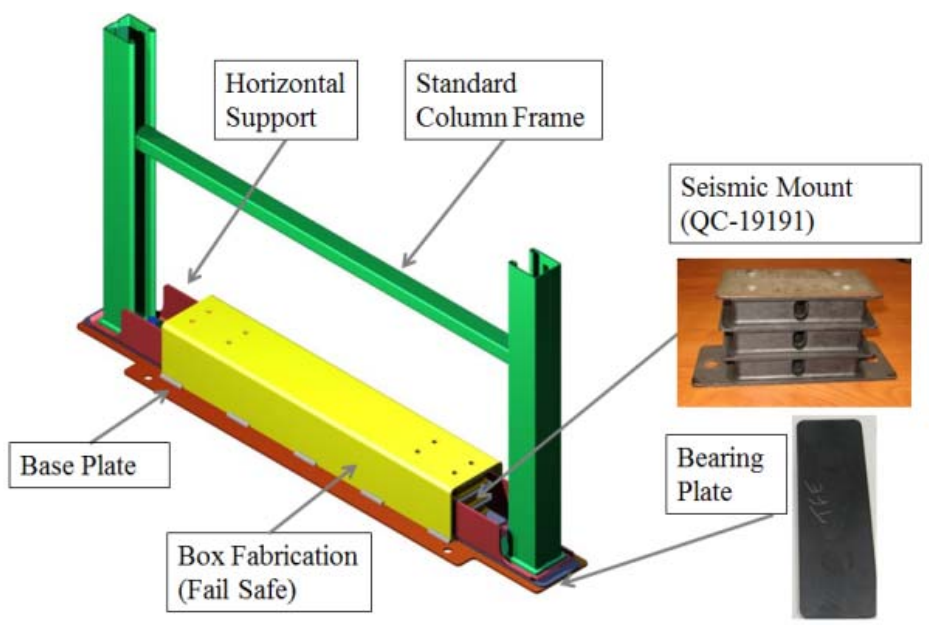

(b)

Figure 10: Pellegrino ${ }^{\circledast}$ device (a) (font https://www.ridgurak.com/). Rendered view of the base isolation system Pellegrino $^{\oplus}$ for steel storage racks. The principal components are given (b) [55]

Table 1

Principal characteristics for the Pellegrino base isolation system [40]

\begin{tabular}{l|l|l|l|l}
\hline $\begin{array}{l}\text { Rubber } \\
\text { durometer }\end{array}$ & $\begin{array}{l}\text { Shear stiffness } \\
{[\mathrm{kN} / \mathrm{m}]}\end{array}$ & $\begin{array}{l}\text { Equivalent } \\
\text { damping ratio }\end{array}$ & $\begin{array}{l}\text { Compression } \\
\text { stiffness } \\
{[\mathrm{kN} / \mathrm{m}]}\end{array}$ & $\begin{array}{l}\text { Max lateral } \\
\text { displacement } \\
{[\mathrm{mm}]}\end{array}$ \\
\hline 40 & 47 & 0.20 & 373 & 100 \\
60 & 93 & 0.22 & 634 & 100 \\
\hline
\end{tabular}


Laboratory (SEESL) at the University at Buffalo (US). Several loading distributions were considered and the tests were repeated with increasing intensity of earthquakes. First of all, natural periods of all the tested racks have been determinate via pulse tests. Full-cycle acceleration time-history at a frequency of $10 \mathrm{~Hz}$ and amplitude of $0.05 \mathrm{~g}$ was generated by the shake table in the three orthogonal directions of the rack to assess the fundamental periods of vibration, which are collected in Table 2. Tests have been conducted by using different type of weights to simulate the stored products: concrete blocks of $21.8 \mathrm{kN}$ of weight each, light merchandise (23.1 kN total), intermediate merchandise (94.1 $\mathrm{kN}$ total) and heavy merchandise (176.5 kN total). In the down-aisle direction fundamental periods of FB racks are significantly longer than those of the cross-aisle (in case of concrete block as pallets e.g. $1.30 \mathrm{~s} v s \mathrm{~s} 0.57 \mathrm{~s}$ ). In case of light merchandise, the cross-aisle period for FB rack results very small, highlighting the really low value of the weight used for this case. For the base isolated rack configurations, the cross-aisle fundamental periods are much longer than the cross-aisle periods of the conventional rack configurations. Conversely, the periods along the down-aisle direction are slightly longer than those of the FB configurations, meeting the objective of providing base isolation in one direction only.

\section{Table 2}

Measured initial fundamental periods of rack specimens [40]

\begin{tabular}{|c|c|c|c|c|c|}
\hline \multirow{2}{*}{$\begin{array}{l}\text { Test } \\
\text { Series }\end{array}$} & \multirow{2}{*}{$\begin{array}{l}\text { Rack configu- } \\
\text { ration }\end{array}$} & \multirow{2}{*}{$\begin{array}{l}\text { Base Isolator Rubber } \\
\text { Durometer }\end{array}$} & \multirow[t]{2}{*}{ Loading } & \multicolumn{2}{|c|}{ Fundamental period (s) } \\
\hline & & & & Down-aisle & Cross-aisle \\
\hline $\begin{array}{l}1 \mathrm{~A} \\
1 \mathrm{~B}\end{array}$ & $\begin{array}{l}\text { Base isolated } \\
\text { Fixed based }\end{array}$ & $\begin{array}{c}60 \\
N / A\end{array}$ & Concrete blocks & $\begin{array}{l}1.37 \\
1.30\end{array}$ & $\begin{array}{l}1.71 \\
0.57\end{array}$ \\
\hline $\begin{array}{c}2,10 \\
6\end{array}$ & $\begin{array}{l}\text { Base isolated } \\
\text { Fixed based }\end{array}$ & $\begin{array}{c}40 \\
N / A\end{array}$ & Light Merchandise & $\begin{array}{l}0.59 \\
0.47\end{array}$ & $\begin{array}{l}1.45 \\
0.19\end{array}$ \\
\hline $\begin{array}{l}3 \\
7\end{array}$ & $\begin{array}{l}\text { Base isolated } \\
\text { Fixed based }\end{array}$ & $\begin{array}{c}40 \\
N / A\end{array}$ & $\begin{array}{l}\text { Intermediate Mer- } \\
\text { chandise }\end{array}$ & $\begin{array}{l}0.89 \\
0.79\end{array}$ & $\begin{array}{l}1.75 \\
0.46\end{array}$ \\
\hline $\begin{array}{c}4 \\
5,9 \\
8,11\end{array}$ & $\begin{array}{l}\text { Base isolated } \\
\text { Base isolated } \\
\text { Fixed based }\end{array}$ & $\begin{array}{c}40 \\
60 \\
\mathrm{~N} / \mathrm{A}\end{array}$ & Heavy Merchandise & $\begin{array}{l}1.14 \\
1.12 \\
1.00\end{array}$ & $\begin{array}{l}1.71 \\
1.75 \\
0.55\end{array}$ \\
\hline
\end{tabular}

The synthetic seismic input has been generated starting from the maximum considered earthquake (MCE) demand for a site Class D in a high seismic zone (e.g. California), given in the FEMA 460 document [20] where is defined also the Design Earthquake (DE) for the life safety performance. In particular, the $150 \%$ seismic input level meets the MCE $(0.7 \mathrm{~g})$ and the $100 \%$ meets the DE $(0.47 \mathrm{~g})$. Observing the results of the seismic tests, they have clearly demonstrated the improved structural performance of a rack structure incorporating a cross-aisle base isolation system. The base isolation system considered in this study significantly reduced the cross-aisle absolute accelerations and inter-storey drifts (Figure 11) of the rack structure compared with the values measured in the same rack conventionally anchored at its base. For the rigid base rack, an inter-storey drift of $4 \%$ occurred at the first level of the rack. As it may be clear, the structure exhibits a soft-storey failure mechanism which is the worst scenario ever. On the other hand, the base 


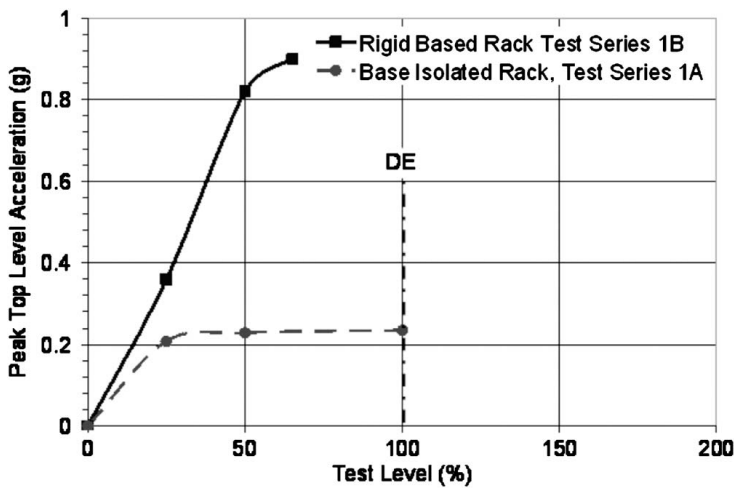

(a)

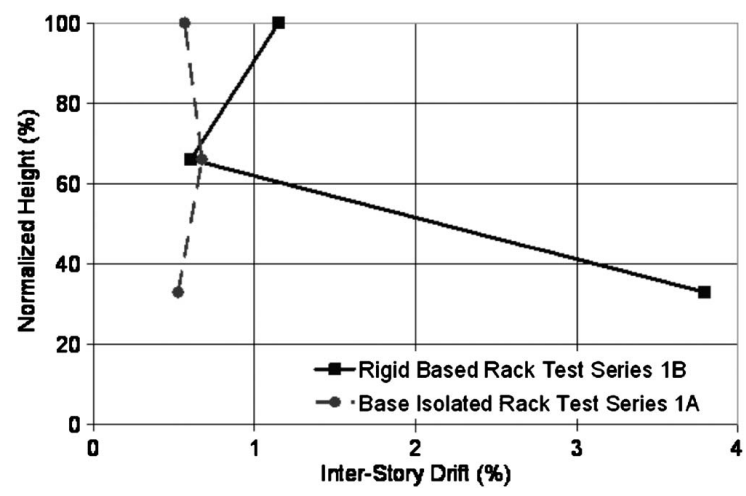

(b)

Figure 11: Variations of peak top level cross-aisle accelerations with excitation amplitudes (a), and envelopes of peak cross-aisle interstorey drifts, cross-aisle seismic excitations (b), 50\% test level, Test Series 1A and 1B. [40]

isolated configuration shows that the inter-storey drift remains under $0.7 \%$ at all levels (Figure 11).

Although the base isolation system is designed to isolate the rack in the cross-aisle direction, it has also some beneficial effects in reducing the accelerations of the racks in the down-aisle direction, up to 1.5 and 2.1 times lower for light and heavy merchandise, respectively. This beneficial effect is due to the slight increase in the down-aisle natural period of the racks (Table 2). The efficiency of the base isolation system in reducing the cross- and down-aisle accelerations increases with the weight of the merchandise.

For the base isolated rack configurations no overturning of the merchandise during triaxial excitation, corresponding to $100 \%$ test level (life safety performance), has been observed. Under a triaxial seismic excitation at $200 \%$ test level, the base isolated rack loaded with light merchandise recorded an item falling from the topmost level. On the other hand, the base isolated rack loaded with heavy merchandise did not sustained any loss. Under the same $200 \%$ triaxial excitation, the rigid based rack did lose almost all of the stored items (last frame of Figure 4). Moreover, the conventional (rigid based) racks suffered significant structural damage as a result of the triaxial seismic tests. Following a triaxial seismic excitation at $65 \%$ test level, yielding, local buckling and cracking at the base of the central uprights were observed (Figure 12(a)). On the other hand, damage on the base isolated structure, for the case with heavy merchandise, cracking and tearing across down-aisle connector perforations in uprights was observed (Figure 12(b)).

During the seismic test at $150 \%$ test level, both central uprights sheared off completely from their base plates just above the welds. Finally, it was judged that the rigid based racks did not meet the expected performance objectives recommended in the FEMA 460 document since serious structural damage occurred at intensity less than the DE. 


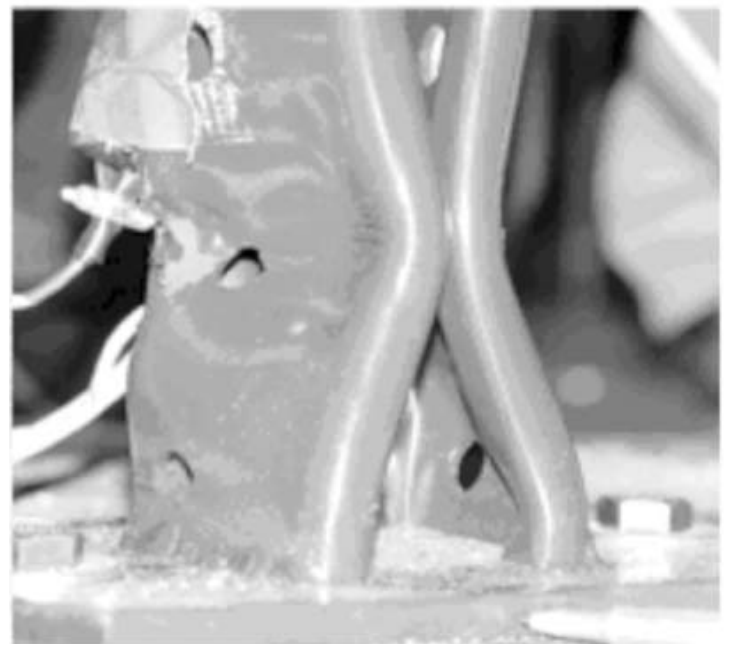

(a)

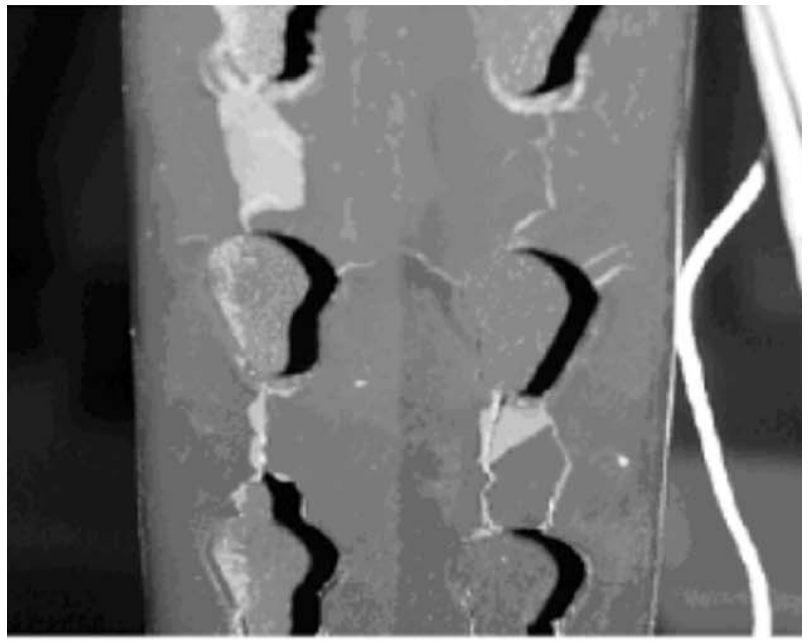

(b)

Figure 12: Buckling of central upright of rigid based rack, Test Series 1B, 65\% test level (a). Cracking and tearing across down- aisle connector perforations in uprights of base isolated racks following Test Series 5 and 9, 200\% test level (b) [40].

\subsection{Loki base system}

LOKIBASE is an isolator device developed mainly for steel storage pallet rack structures and it works in both down- and cross-aisle directions [http://www.lokibase.com, accessed 2020]. It consists of the following main components (Figure 13(a)): i) two slider devices on which a rubber membrane is set up (LOKI devices); ii) a beam damper (called CANDLE); iii) two anti-lifting devices (UP-LIFT); iv) a fuse plug. The two slider devices, rigid in the vertical direction and with low friction resistance in the horizontal one, allow to support vertical loads and decouple sliding planes, thanks to marble bearing systems. The rubber membrane is intended as an elastic element capable of providing recentring forces, which tend to mend the residual displacement of the system after a seismic event. Tensile forces are not carried by the system and, for these reason, two anti-lifting frames are provided on each upright frame. A fuse plug is mounted on each upright frame, used to avoid small oscillations during normal conditions of the picking operations. As it appears clear from Figure 13(a), the LOKIBASE is a compound of several devices, and needs to be put in place in order to make up the whole isolator. Despite this, neither the website nor the 2 papers provide any detail but for the LOKI itself and the CANDLE element. As a consequence, no further information can be grasped from the available material on the behaviour of the UP-LIFT frames and the CANDLE within a seismic framework.

During the years of its development several experimental tests have been performed, which are useful to characterise its hysteretic behaviour. The theoretical characterisation of the system is available in two companion papers [56, 57]. The first [56] focuses on the analysis of the cylindrical beam damper (CANDLE), whose experimental tests were run 


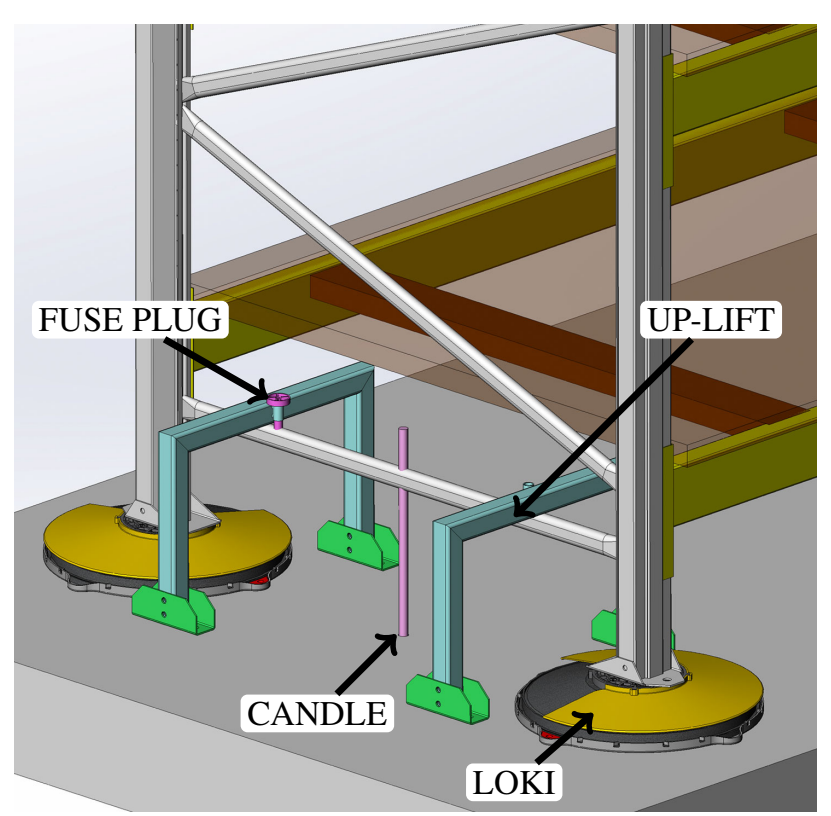

(a)

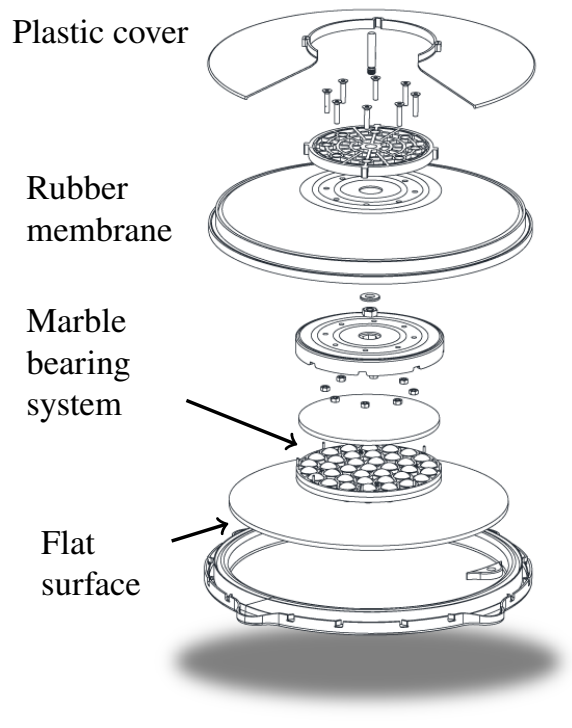

(b)

Figure 13: LOKIBASE system with its principal components (a); Internal component of LOKI device (b)

at University of Trento Laboratory (Italy), and then provides a theoretical model for the fully operating device. The latter [57] mostly deals with the optimisation of the beam damper, considering two different cross sections i.e. circular and double circular. In fact, the main aim of this is to funnel into the device the capability of having two different stiffnesses along the cross- and down-aisle direction, respectively. From the reanalysis of the results of the proposed device, which are obtained with the double circular section, it can be noted that:

- in the cross-aisle direction, the secant stiffness at the maximum design displacement is equal to $21.20 \mathrm{~N} / \mathrm{mm}$ with an equivalent viscous damping ratio $\xi=0.25$;

- in the down-aisle direction, the secant stiffness is $15.90 \mathrm{~N} / \mathrm{mm}$ with an equivalent viscous damping ratio $\xi=0.16$;

where the maximum design displacement for the tested specimen is $174 \mathrm{~mm}$.

The results exposed in the two papers - [56] and [57] - refer to cyclic tests carried out on the element called CANDLE, though. The results of the tests confirmed that the device can be designed to provide different stiffness along each main direction, so giving the chance to make it suit to different requirements. However, it must be noticed that results of the theoretical model are not thoroughly inferred, for it is not straightforward to extrapolate the behaviour of the whole device as in place from just the tests on the dissipative element. The membrane, which is the recentring system, was not in place when the tests were performed henceforth the elastic stiffness of the system must be different. If the membrane geometry is taken into account, a non linear component may rise due to its non-symmetrical deformed shape. Also, the anti-lifting system has not tested. In order to provide a complete physical characterisation, the whole 

far, despite they being of great interest.

\subsection{IsolGOODS ${ }^{\oplus}$ isolation system} system was subjected to characterisation tests similar to those required by the European Standard on Anti-seismic devices [41]. Furthermore, the performance of the isolation system has been assessed by means of shake table test performed at the FIP Laboratory Tests (Italy). A one-bay four-storey pallet rack was equipped with the presented isolation system and its dynamic behaviour was studied under a set of ground motions. Unfortunately, neither the re-

Finally, some footage of full-scale tests are reported on [http://www.lokibase.com, accessed 2020] focused on the comparison between an isolated and a non-isolated structure, under seismic actions: i) for a barrel-wine rack (similar to the ones discussed in Section 3.2); ii) for a one-bay four-storeys steel storage rack. The earthquake has been simulated by a bi-directional shake-table. The tests on storage pallet racks have been conducted with different typology of pallets. It is remarked in a really clear way the capacity of this system to dissipate in both cross- and down-aisle direction, as it fits the purpose of the LOKIBASE system. Two principal differences can be noted from the short movies: with no isolation the displacements are bigger than the ones observed with the isolation and overturning of top pallets happens only in non-isolated frame. Unfortunately no more detailed test results have been published so

FIP MEC (formerly FIP Industriale) has recently developed a system, named with the trademark IsolGOODS ${ }^{\circledR}$, specific for the seismic isolation of adjustable pallet racking systems.

Figure 14 depicts an unidirectional seismic isolation device suitably designed and patented, which provides seismic isolation to the rack in the cross-aisle direction only, similarly to the system described above in Section 3.3. As already discussed, the fundamental period of the rack in the cross-aisle direction is usually much lower than in the down-aisle direction, and thus this direction is the most affected by earthquake-induced effects. That is why this system provides seismic isolation only in the cross-aisle direction, while the behaviour in the down-aisle direction remains mostly unaltered. This allows to use the pallets slots at ground level, as in a conventional pallet rack, while said pallet slots are lost when using multi-directional isolators. Additionally, the system is able to prevent the up-lift of the rack, that could happen in particular load cases under high seismicity actions, in particular in single-entry pallet racks. IsolGOODS ${ }^{\circledR}$ working principle is that of a pendulum isolator or Curved Surface Slider (CSS) as defined in [41], with a double or single surface of sliding. Low-lateral flexibility is guaranteed by a low-friction material. In fact, FIP uses for this device a particular material, i.e. FIP friction material (FFM), which is an ultra-high molecular weight poly-ethylene (UHMW-PE) that ensures very high load-bearing capacity and wear resistance [58].

As it is well known, CSS devices inherently provide a restoring capability related to the radius of curvature, while energy dissipation is provided through friction. The most important feature is that the fundamental period of a structure isolated through CSS is independent from the mass. This is of particular interest for racks, whose mass distribution is mostly unknown and its high variability may pose an issue to identify the worst load-scenario. The IsolGOODS ${ }^{\circledR}$ 


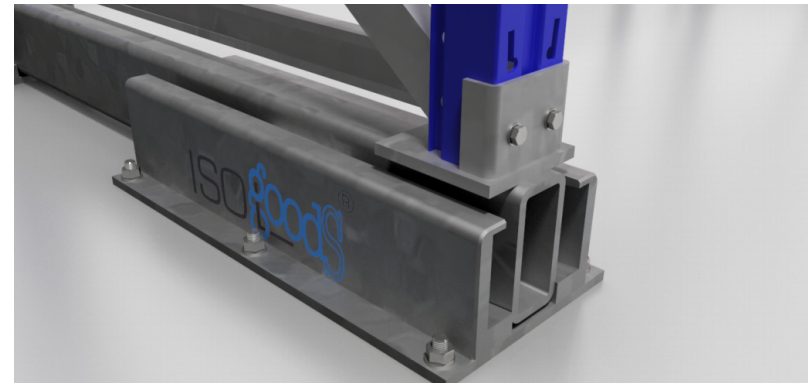

(a)

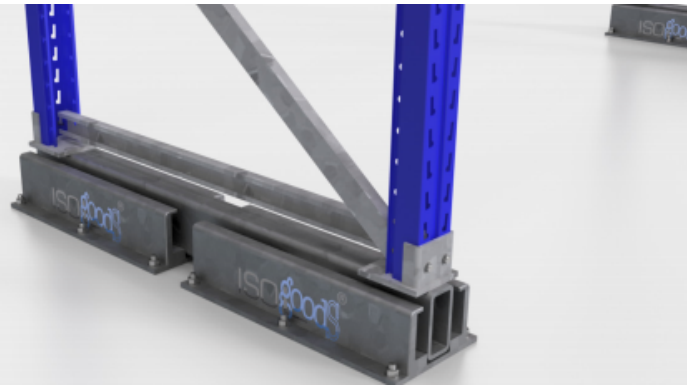

(b)

Figure 14: Render views of the IsolGOODS ${ }^{\circledR}$ device (a) and installed under a single-entry pallet rack (b). (courtesy of FIP MEC s.r.l.) sults of these tests nor a detailed description of the device have been published yet and consequently, no more specific information can be given. 

a negligible hardening phenomenon and experiencing no damage. For seismic resistant structures, such devices are commonly embedded into braces [59], beam-to-column joints [60] and into column-base joint [61]. A novel dissipation joint has been very recently proposed by Tang et al. [62] for pallet racking systems. The low-cost method proposed in this paper is based on the insertion of a steel sliding friction base-plate connected to all the uprights (Figure 15(a)), developed for low and medium-rise racks. The proposed system has been compared with the most commonly used yielding base-plate [13]. The device [63] (Figure 15(d)) is able to dissipate energy thanks to the friction instead of forming yielding zones at the base connections, which generally has to be replaced after the earthquake. Friction is introduced via a controlled clamping force between the upright and a stub welded to the base-plate. Of course, each grade of tightness of the bolts produces a different base response.

Full scale snap-back tests have been performed considering four different base-plate joints, which are installed at the base of a one-bay three-deck pallet racking system. The connection typologies involved in this campaign are (Figure 15): i) rigid or fixed base-plate (FB) 15(b); ii) yielding base-plate (YB) 15(c); iii) Friction base-plate with bolt tightening (DB) 15(d); iv) Friction base-plate without bolt tightening (WB) 15(d). The initial displacement was imposed at the third deck of the structure and equals $100 \mathrm{~mm}$ along the cross-aisle direction, which, as it has been stressed before, presents more lateral stiffness. The reason of only one direction is fairly clear. Though the sliding friction device can work in both directions, it needs the upright engaged into tension to be activated.

Figure 16 shows the test results. Permanent local deformations have been observed in FB frames that cause a large residual drift (dashed blue line), which is around $30 \mathrm{~mm}$ (tail of the dashed blue line), and it must be the one imposed 


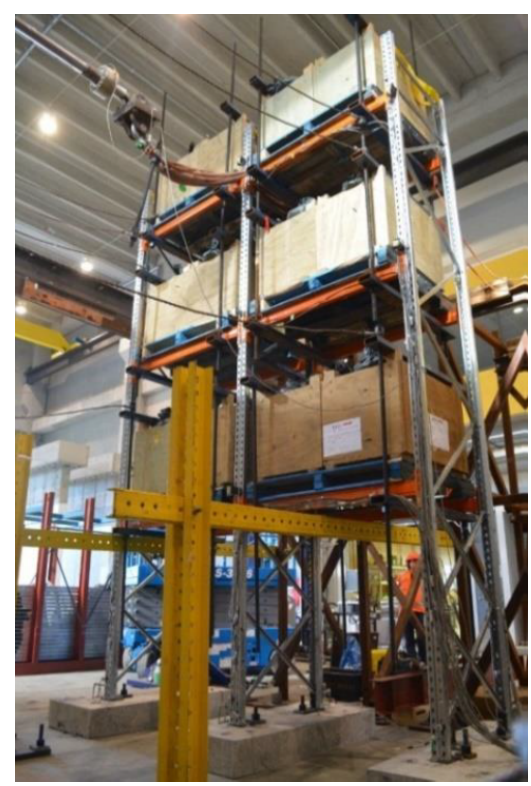

(a)

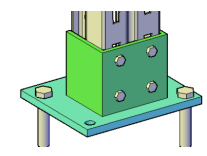

(b)

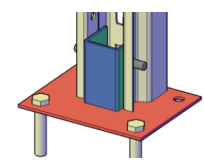

(c)

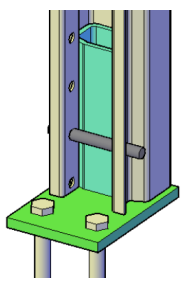

(d)

Figure 15: (a) Test setup of the fully loaded frame; sketches of the three connections compared: (b) rigid base-plate, (c) yielding base-plate and (d) friction base-plate

by the actuator. It can be seen that the most of the kinetic energy is dissipated within the first cycle. In all the other cases, no damage, apart from the base-plates themselves, has been observed and the initial residual displacements were recovered even if the tests were started with the same imposed displacements. Rocking was observed for the frames fitted with YB (dashed orange line), DB (dotted black line) and WB (solid red line). Additionally, a first attempt to calculate the equivalent damping ratio from the free-vibration responses has been made by the Authors by using the logarithmic decrements method upon the first 3 cycles. The calculations reveal that the ratio is equal to $16.3 \%$ for FB frame (that is quite large) and 20\% for WB frame, whereas for YB and DB is equal to almost 7\%. Finally, the oscillation of internal axial force on the uprights has been recorded by using strain gauges. It has been shown that uprights of both DB and WB frames had smaller force demand compared to YB one. The amount of the compression force on the FB is 1.5 times greater than the other cases.

By comparing the performance of the devices, it is not immediate to choose the outperformer. From the results outstandingly exposed in this paper, the friction sliding devices behave better than the yielding base-plate and far better than the fixed base-plate. According to the Authors, the bolt-tightened one gives more seismic resilience and is capable of reducing the force demand. However, it must be kept in mind that the tests are performed considering a dynamic framework not a seismic one. The structure equipped with the YBs proves to be as stiff as the one with the FBs, while the structures with DBs and WBs exhibit periods that are almost twice the FB's. This is indeed an advantage, for the structure does benefit of a period shift. 


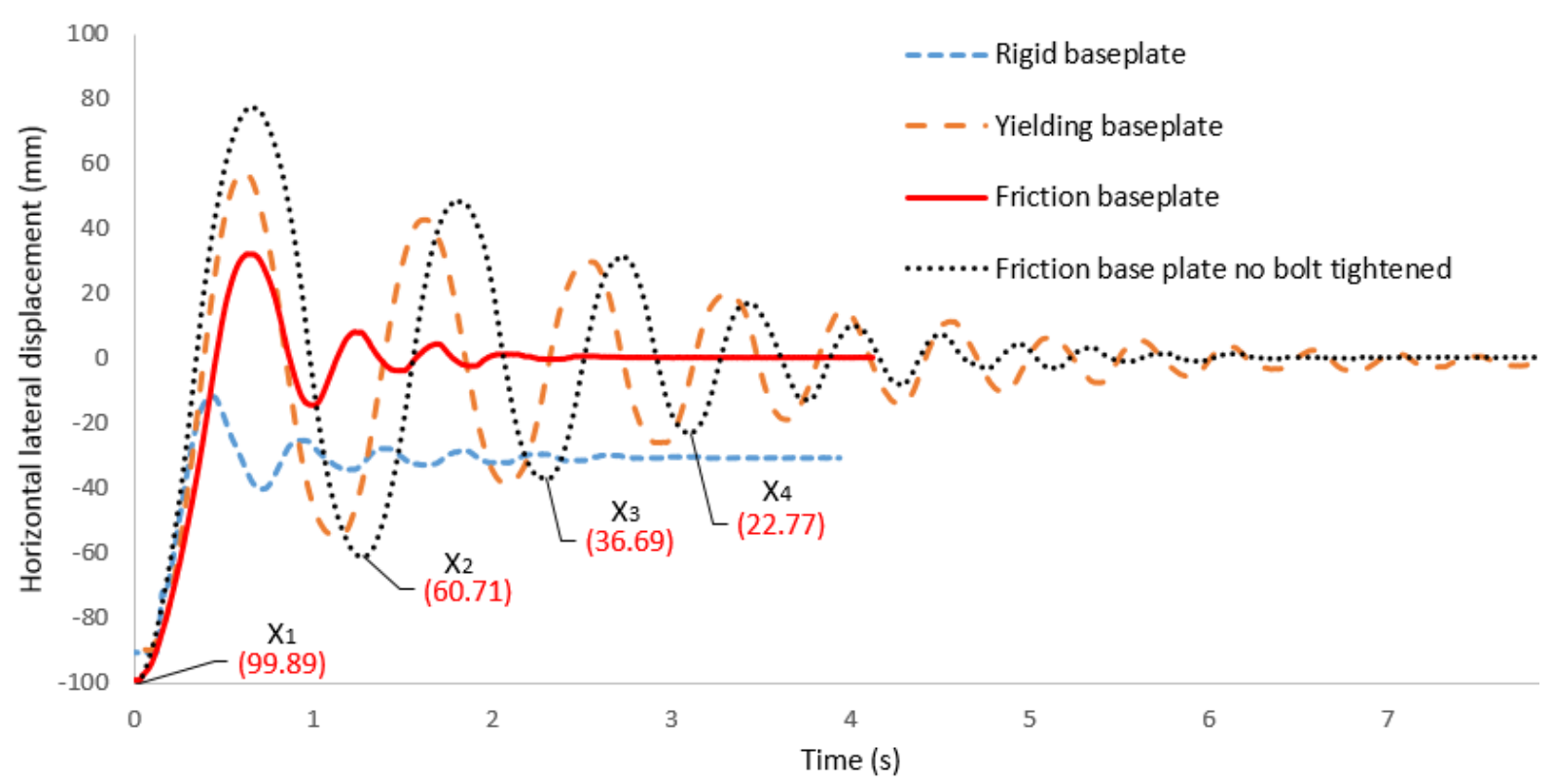

Figure 16: Seismic test results available in [62]: time-history of horizontal displacements of the middle upright frame with 4 types of base-plate configuration

\subsection{Drive-in racks}

Drive-in and Drive-through racks are special typologies of steel storage systems developed to maximise the storage density. In the drive-through, as suggested by the name, operators can go through the structure in the aisle-direction, from both sides, while in the drive-in type, one side is for the forklift operation and the other face is braced (to improve the stability of the system). The principal difference between drive-in and pallet racks is that in the former no interstorey beams are present, making the structure more susceptible to instability phenomena. Global stability is therefore obtained mainly thanks to the base-plate connections and to the beams present on top.In fact, at the top of the structure, a bracing plane is realised which acts as a rigid diaphragm. The pallet itself contributes to give more stability to the frame system, as studied by many authors [64]. At the Sydney University, Australia, the first world-wide seismic full-scale shake table tests on drive-in frames (Figure 17) have been performed [65]).

The objectives of the study were to determine the natural frequencies and damping ratios from full-scale shake table tests as well as the inelastic responses of drive-in rack frames when subjected to seismic excitation. Also modes of vibration, base shear and damage propagation have been investigated. In the first paper [65], two different framing systems have been considered: one fully braced in the cross-aisle direction with the diagonal braces extending from top to bottom; the second one relying mainly on a portal frame type of stiffness and bending capacity of uprights in resisting the earthquake-induced actions. The interesting results showed how plasticity is propagated along these particular structures before the structural collapse, identifying all the damages spread on braces and uprights.

To improve the seismic reliability [66], special steel dissipation devices could be mounted to an external spine 


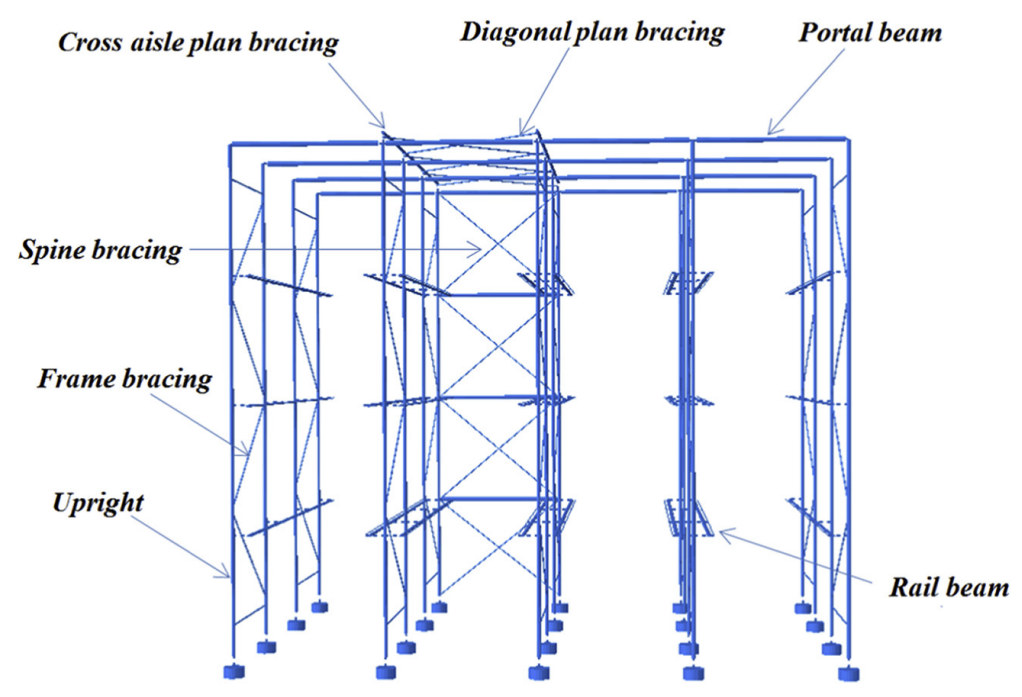

Figure 17: Terminology of drive-in racking system [65]

bracing system. The device is a special steel plate that permits to mitigated the seismic actions while preserving the structural integrity of the principal components.

\subsection{Parmigiano cheese}

The great number of collapses happened after the 2012 Emilia-Romagna earthquake (Italy) [67], showed the low reliability of the seismic zoning map for design which was in-force before 2003. The majority of the economical losses were experienced by the business sector [23], due to the collapse of many industrial buildings [68]. The poor performance of these structures, which were not designed to withstand lateral actions, led many researchers to concentrate their attention on new recommendations for retrofitting the existing ones [69]. The seismic event also underlined the need for seismic provisions to be applied to non-structural elements [23] (figure 18(b)). Theoretical research are in

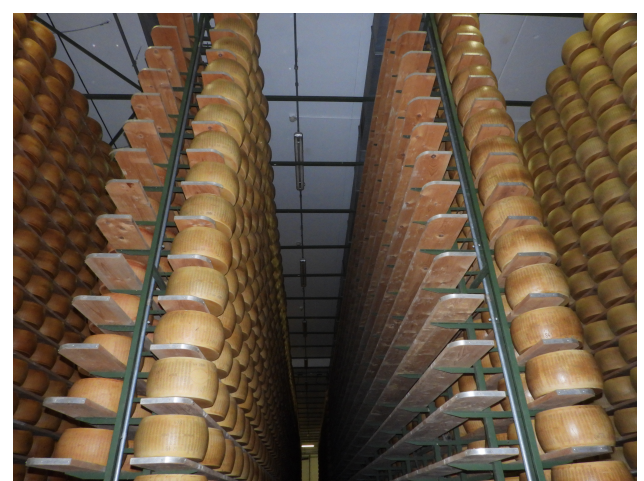

(a)

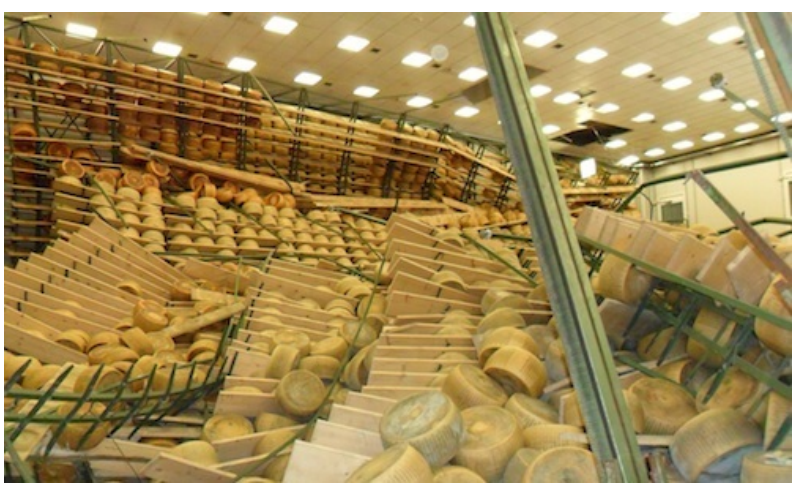

(b)

Figure 18: Typical storage system for Parmigiano cheese (a) and a collapsed one after something (b) 


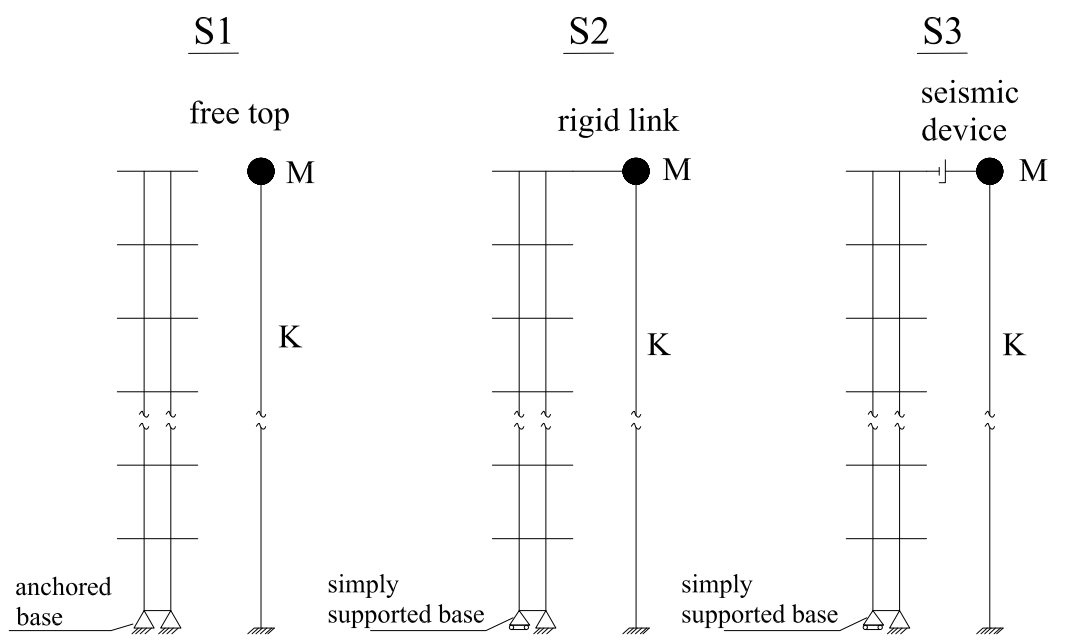

(a)

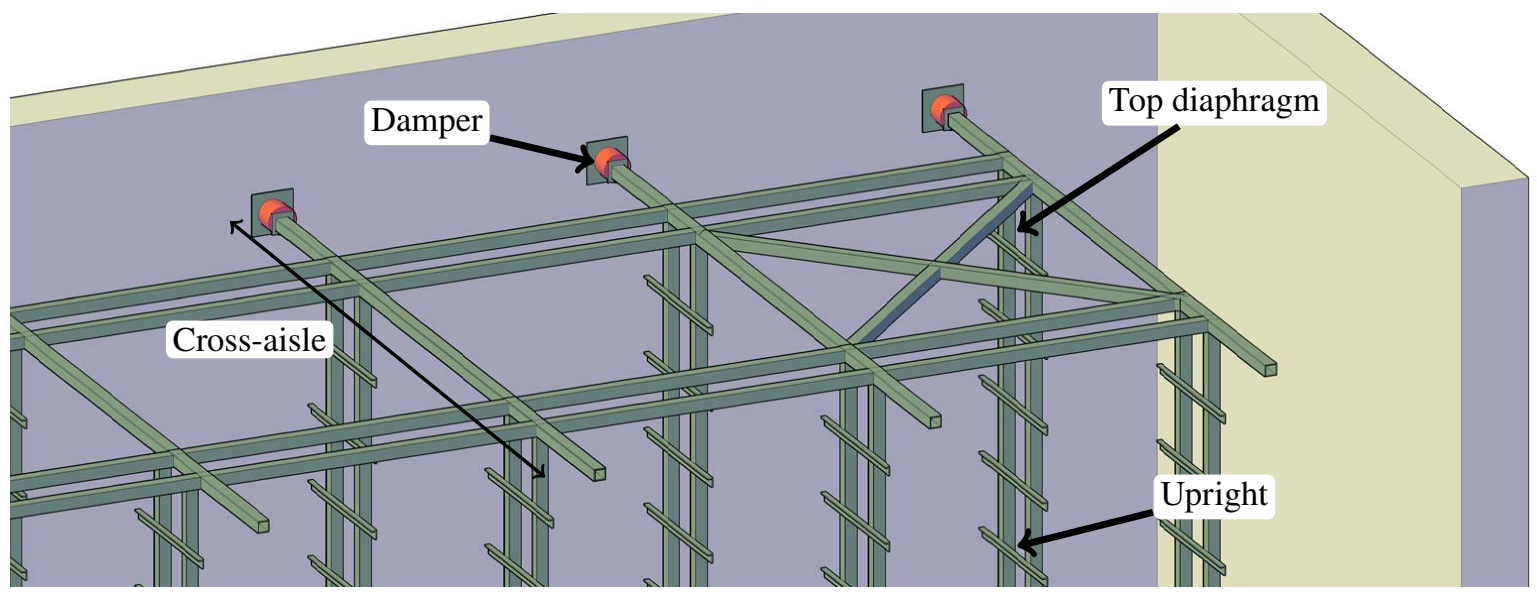

(b)

Figure 19: Three structural models that can be considered to simulate the scalere in the cross-aisle direction (a). Render view of case $S 3$, which shows in red the damper devices after Franco et al [70] (b).

progress also in the field of the steel structures for the storage of the Parmigiano cheese (Figure 18(a)), which is a very important Italian product. 
these structures have been designed more than 20 years ago, considering only vertical forces (with no seismic actions) and therefore they are generally in an unsafe condition. For this reason, Franco et al. [70] proposed a complete study on the dynamic behaviour of these racks, focusing the attention on the seismic improvements techniques. The cases $S 1$ and $S 2$ exposed in Figure 19(a) are representative of the way this structures are often built. A proposed solution by the Authors is to use a passive-control system: viscous dampers are connected between the top of the storage racks and the surrounding concrete structures ( $S 3$ in Figure 19(a)).

The time-history analyses of the proposed configurations have shown that the use of dampers presents noteworthy advantages for all cases in which the constraint degree of the racks is augmented and, consequently, their stiffness is increased. The advantages are in terms of stress reduction in the rack elements, and of reaction forces transmitted to the surrounding support structures. A sensitivity analysis has also been conducted to assess the optimal damping factor for the viscous coupling. An optimal damping condition is the one in which the bending moments in the longitudinal and transversely directions are comparable and, at the same time, the forces transmitted to the surrounding support structures are contained. A passive-control system, which provides the viscous coupling of the existing racks with a surrounding support structure, increases the seismic performance in terms of both stress and displacements. This countermeasure is simple and economical, because the refurbishment can be made without moving the cheese wheels, thus eliminating the cost for retaining the warehouse. On the minus side, this strategy requests to modify the dynamic behaviour of the adjacent structure, which will need in turn to be checked against the forces transmitted by the devices.

\subsection{Warehouse}

Takeuchi and Suzuki [71] studied a high-rise automatic steel rack warehouse (height 52m) replacing side base chords (Figure 20) of the centre truss, by buckling resisting columns (BRC).

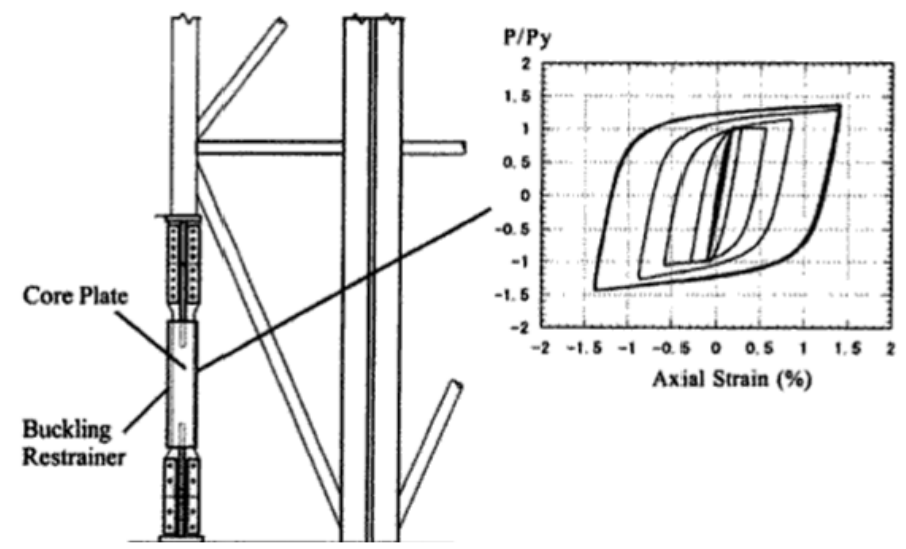

Figure 20: BRC system and its hysteresis loop [71]

The collapse mechanism of the entire structure is hence dictated by the BRC: during an earthquake, the side trusses are kept elastic while BRCs are going into plastic and pull back the structure from residual deformations. The BRCs 
are composed of steel core-plates restrained with a concrete-filled tubes. The restrain keeps the core-plate away from buckling and therefore its behaviour is symmetric, showing a very excellent energy dissipation behaviour. The performance of the structures against large earthquakes is greatly improved if compared to the same warehouse without BRCs: replacing only 2 columns over 13 with BRCs makes the maximum shear forces reduce to $75 \%$, while replacing 6 over 13 reduce to $55 \%$.

\section{Concluding remarks}

The major seismic codes used in the rack design, EN16618 and FEMA460, provide recommendations to increase the seismic safety of rack structures but do not give any provision about the base isolation systems. If overturning of stored goods is of concern, there are only two ways reported for the improvement of the safety of racks in seismic zones: rack netting and structural strengthening. The rack netting is a steel netting installed on all sides of the rack, covering the bay openings from top to bottom. Though effective, the method is also very impractical for several reasons. In fact, if netting is installed, it then needs to be removed and reinstalled every time a storage slot is accessed. As regards the latter provision, it can be noted that it allows the structure to meet the code requirements but increases the stiffness of the structure at the same time, adding rigidity and introducing higher accelerations throughout the system. The two approaches can be used together, but neither rack netting nor structural strengthening protect the rack and prevent adequately the product shedding. The product shedding prevention must be always considered in the design process, being the total cost of stored goods generally much higher than the cost of the structural components. Also in this direction, seismic isolation seems to be a very useful and effective solution, and a number of researches are nowadays in progress in many parts of the world.

The paper has presented the main characteristics of several devices applied to different typologies of steel storage racks. The research of Kilar et al. [45] shows that the use of base isolation for high rack structures does reduce the inter-storey displacements and the dangerous effects of torsion. An application of a standard base isolation system to a high rack structure is presented, which has been treated on a par with classical buildings. Then base isolation of wine barrels is discussed, following the papers published by Chadwell et al. [54]. Despite the developed device being clearly efficient, in the process of its development no attention was paid neither to limiting lateral displacements nor to the re-centring capacity after an earthquake. In spite of having such limitations, the system proved to be highly effective. Regarding the base isolation of classical steel storage pallet racks, the RIGID-U-RAK system (Pellegrino ${ }^{\circledR}$ ), the FIP MEC System (IsolGOODS ${ }^{\circledR}$ ) and the Gilardini System (LOKIBASE) have been discussed. Both the IsolGOODS ${ }^{\circledR}$ system and the Pellegrino ${ }^{\oplus}$ system are unidirectional; conversely, the LOKIBASE system is a bi-directional device that hence affects both directions. Though a complete description of the devices was provided, the only available results in the literature for real applications are from the Pellegrino ${ }^{\circledR}$ system [40]. The results show that the application of a seismic isolation system can reduce accelerations on both cross- and down-aisle directions, avoid the overturning of 

in the collected research. a safe in-service use also after the seismic events. the well-established building practices.

\section{References}

the stored goods and damage on the uprights. Finally, the use of energy dissipation devices is discussed. It can be an effective and low-cost solution as demonstrated by Tang et al. [62], Franco et al. [70] and Takeuci et al. [71]. Devices of such kinds can provide rack structures with more resilience, for the design and retrofit of structures as it is shown

Unfortunately, The detailed characteristics of some presented systems cannot be easily found because no paper has been published so far. However, on the companies' websites, some photos and video shootings are reported during several experimental tests. Despite the peculiarity of rack structures, a base isolation system can bring many advantages, such as the reduction of accelerations on both cross- and down-aisle directions, the reduction of the inter-storey drifts and the prevention of the overturning of the stored goods. Another important aspect is related to the energy dissipation during earthquakes. In fact, normally the energy dissipation is concentrated only on the beam-to-column joints that are subjected to great damage during the earthquake. The use of dissipative devices or base isolation systems increases the energy dissipation reducing the plastic rotation in the joints and consequently the structural damage, guaranteeing

To conclude, another issue must be underlined. Purposely provided devices to a code-compliant structure, whose seismic response is modified by them, have to comply with the current law in the Country where the structure is erected. For instance, throughout the European countries, the seismic devices are built and installed in accordance with the European Standard on Anti-seismic devices [41], which identifies functionalities, design rules and conformity requirements for the devices to be used. To be practical, the devices, which have been reviewed in this manuscript, need to be indeed code-compliant as well. However, the Pellegrino ${ }^{\circledR}$ and IsolGOODS ${ }^{\circledR}$ devices seem to be the only two seismic isolators which can fit both the no failure requirement (NF) and damage limitation requirement (DL). The LOKIBASE, on the contrary, relies on a plastic hinge to provide the device with a dissipative behaviour which violates the DL requirement. The device proposed by Chadwell et al. [54] cannot be easily framed into the [41] classification, though. In this framework, it presents several issues related to the definition of concrete-ball friction coefficients, for the bottom surface does not come with the device. The wear resistance poses a problem as well, since while the ball rolls and slides the concrete tends to be scratched, unpredictably changing its characteristics. Needless to say, the devices used for the case study of [46], the buckling restrained columns (BRC) and the dampers come directly from

[1] K. Tilburgs, Those peculiar structures in cold-formed steel: "racking \& shelving", Steel Construction 6 (2013) 95-106. URL: https: //onlinelibrary.wiley.com/doi/abs/10.1002/stco.201310016. doi:10.1002/stco.201310016.

[2] V. Vlasov, Thin-walled Elastic Beams. $2^{\text {nd }}$ Rev. Enl.ed, 1961. URL: https://books.google.it/books?id=EjBMAQAACAAJ.

[3] W. Chen, T. Atsuta, Theory of beam-Columns: vol. 2 Space behaviour and design, 1977.

[4] EN 15512, Steel Static Storage Systems - Adjustable Pallet Racking Systems - Principles for Structural Design, European Committee for 
Standardization, Brussels, 2009.

[5] EN 16681, Steel Static Storage Systems - Adjustable Pallet Racking Systems - Principles for Seismic Design, European Committee for Standardization, Brussels, 2016.

[6] EN 1993 (Eurocode 3), Design of Steel Structures, European Committee for Standardization, Brussels, 2005.

[7] ANSI/AISC 360-16, Specification for structural steel buildings, American Institute of Steel Construction, US, 2016.

[8] C. Bernuzzi, A. Pieri, V. Squadrito, Warping influence on the static design of unbraced steel storage pallet racks, Thin-Walled Structures 79 (2014) 71 - 82. URL: http://www.sciencedirect.com/science/article/pii/S0263823114000342. doi:https://doi.org/10. $1016 / j$.tws. 2014.01 .024

[9] A. Filiatrault, P. S. Higgins, A. Wanitkorkul, Experimental stiffness and seismic response of pallet-type steel storage rack connectors, Practice Periodical on Structural Design and Construction 11 (2006) 161-170. doi:10.1061/(ASCE) 1084-0680 (2006) 11:3(161).

[10] C. Bernuzzi, C. A. Castiglioni, Experimental analysis on the cyclic behaviour of beam-to-column joints in steel storage pallet racks, Thin-Walled Structures 39 (2001) 841 - 859. URL: http://www. sciencedirect.com/science/article/pii/S0263823101000349. doi:https://doi.org/10.1016/S0263-8231(01)00034-9.

[11] C. Bernuzzi, M. Simoncelli, An advanced design procedure for the safe use of steel storage pallet racks in seismic zones, Thin-Walled Structures 109 (2016) 73 - 87. URL: http://www.sciencedirect.com/science/article/pii/S0263823116304876. doi:https: //doi.org/10.1016/j.tws.2016.09.010.

[12] F. Gusella, M. Orlando, P. Spinelli, Pinching in steel rack joints: Numerical modelling and effects on structural response, International Journal of Steel Structures 19 (2019) 131-146. URL: https://doi.org/10.1007/s13296-018-0095-x. doi:10.1007/s13296-018-0095-x.

[13] F. Petrone, P. Higgins, N. Bissonnette, A. Kanvinde, The cross-aisle seismic performance of storage rack base connections, Journal of Constructional Steel Research 122 (2016) 520 - 531. URL: http://www.sciencedirect.com/science/article/pii/S0143974X16301031. doi:https://doi.org/10.1016/j.jcsr.2016.04.014.

[14] C. Chen, R. Scholl, J. Blume, Seismic study of industrial storage racks, report prepared for the national science foundation and for the rack manufacturers institute and automated storage and retrieval systems (sections of the material handling institute). (1980) $569 \mathrm{pp}$.

[15] C. Bernuzzi, A. di Gioia, G. Gabbianelli, M. Simoncelli, Pushover analyses of hand-loaded steel storage shelving racks, Journal of Earthquake Engineering 21 (2017) 1256-1282. URL: https : //doi .org/10.1080/13632469.2016.1210063. doi:10.1080/13632469. 2016.1210063

[16] R. Montuori, G. Gabbianelli, E. Nastri, M. Simoncelli, Rigid plastic analysis for the seismic performance evaluation of steel storage racks, Steel and Composite Structures 32 (2019) 1-19.

[17] FEM 10.2.08, Recommendations for the design of static steel storage pallet racks in seismic conditions, Federation Européenne de Manutention, version $1.00,2010$

[18] AS 4084, Steel Storage Racking, Australian Standards, Australia, 2012.

[19] ANSI MH 16.1, Specification for the Design, Testing and Utilization of Industrial Storage Racks, American National Standard, US, 2009.

[20] FEMA 460, Seismic considerations for steel storage racks located in areas accessible to the public, Federal Emergency Management Agency, Washington, DC., 2005.

[21] J. Crosier, M. Hannah, D. Mukai, Damage to steel storage racks in industrial buildings in the darfield earthquake, Bulletin of the New Zealand Society for Earthquake Engineering 43 (2010). doi:10.5459/bnzsee.43.4.425-428.

[22] D. Perrone, P. M. Calvi, R. Nascimbene, F. E. C., G. Magliulo, Seismic performance of non-structural elements during the 2016 central italy earthquake, Bull Earthquake Eng 17 (2016) 5655 - 5677.

[23] L. Rossi, B. Holtschoppen, C. Butenweg, Official data on the economic consequences of the 2012 emilia-romagna earthquake: a first analysis of database sfinge, Bull Earthquake Eng 17 (2019) 4855 -4884. doi:https://doi .org/10.1007/s10518-019-00655-8. 
[24] I. Connor, Performance of steel storage racks in the darfield earthquake, Bulletin of the New Zealand Society for Earthquake Engineering 45 (2012) 61-70. doi:10.5459/bnzsee.45.2.61-70.

[25] S. Uma, G. Beattie, Observed performance of industrial pallet rack storage systems in the canterbury earthquakes, Bulletin of the New Zealand Society for Earthquake Engineering 44 (2011). doi:10.5459/bnzsee.44.4.388-393.

[26] EN 1998-1-1, Design of Structures for Earthquake Resistance-Part 1: General Rules, Seismic Actions and Rules for Buildings, CEN, 2005.

[27] C. Bernuzzi, M. Simoncelli, Steel storage pallet racks in seismic zones: Advanced vs. standard design strategies, Thin-Walled Structures 116 (2017) 291 - 306. URL: http://www.sciencedirect.com/science/article/pii/s0263823116307960. doi:https://doi.org/ $10.1016 / j$.tws. 2017.03.002.

[28] SEAOC - Vision 2000 Committee, Performance based seismic engineering of buildings, vols. I and II: Conceptual framework, Structural Engineers Association of California, Sacramento, CA, 1995.

[29] I. Avramidis, A. Athanatopoulou, K. Morfidis, A. Sextos, A. Giaralis, Eurocode-Compliant Seismic Analysis and Design of R/C Buildings, volume 38 of Geotechnical, Geological and Earthquake Engineering, $1^{s} t$ ed., Springer International Publishing, 2016.

[30] A. Longo, R. Montuori, V. Piluso, Theory of plastic mechanism control for MRF-CBF dual systems and its validation, Bulletin of Earthquake Engineering 12 (2014) 2745-2775. doi:10.1007/s10518-014-9612-2.

[31] V. Piluso, A. Pisapia, P. Castaldo, E. Nastri, Probabilistic theory of plastic mechanism control for steel moment resisting frames, Structural Safety 76 (2019) 95 - 107. URL: http://www.sciencedirect.com/science/article/pii/S0167473018300407. doi:https: //doi.org/10.1016/j.strusafe.2018.08.003.

[32] M. N. Fardis, Capacity design: Early history, Earthquake Engineering \& Structural Dynamics 47 (2018) 2887-2896. doi:10 . 1002/eqe .3110.

[33] A. De Luca, L. G. Guidi, State of art in the worldwide evolution of base isolation design, Soil Dynamics and Earthquake Engineering 125 (2019) 105722. URL: http://www.sciencedirect.com/science/article/pii/S0267726118310467. doi:https://doi.org/10. 1016/j.soildyn.2019.105722.

[34] K. Ghaedi, Z. Ibrahim, H. Adeli, A. Javanmardi, Invited review: Recent developments in vibration control of building and bridge structures, Journal of Vibroengineering 19 (2017) 3564-3580. doi:10.21595/jve.2017.18900.

[35] J. Takagi, A. Wada, Recent earthquakes and the need for a new philosophy for earthquake-resistant design, Soil Dynamics and Earthquake Engineering 119 (2019) 499 - 507. URL: http://www.sciencedirect.com/science/article/pii/S026772611730876X. doi:https://doi.org/10.1016/j.soildyn.2017.11.024.

[36] P. Pan, D. Zamifrescu, M. Nakashima, N. Nakayasu, H. Kashiwa, Base-isolation design practice in japan: introduction to te post-kobe approach, Journal of Earthquake Engineering 9 (2005) 147-171. doi:10.1080/13632460509350537.

[37] F. Naeim, J. M. Kelly, Theoretical Basis of Seismic Isolation, John Wiley \& Sons, Ltd, 2007, pp. 25-45. URL: https: //onlinelibrary . wiley.com/doi/abs/10.1002/9780470172742.ch2. doi:10.1002/9780470172742.ch2.

[38] C. Christopoulos, A. Filiatrault, Principle of Passive Supplemental Damping and Seismic Isolation, Eucentre, 2006.

[39] A. K. Chopra, Dynamics of Structures: theory and applications to earthquake engineering, 4 ed., Prentice Hall, 2012.

[40] A. Filiatrault, P. S. Higgins, A. Wanitkorkul, J. A. Courtwright, R. Michael, Experimental seismic response of base isolated pallet-type steel storage racks, Earthquake Spectra 24 (2008) 617-639. doi:10.1193/1.2942375.

[41] EN 15129, Anti-seismic devices, European Committee for Standardization, Brussels, 2009.

[42] G. P. Warn, K. L. Ryan, A review of seismic isolation for buildings: Historical development and research needs, Buildings 2 (2012) $300-325$. URL: http://dx.doi.org/10.3390/buildings2030300. doi:10.3390/buildings2030300.

[43] P. C. Roussis, Study on the effect of uplift-restraint on the seismic response of base-isolated structures, Journal of Structural Engineering 135 (2009) 1462-1471. doi:10.1061/(ASCE) ST . 1943-541X. 0000070.

[44] S. Avgerinou, X. Lignos, D. Tsarpalis, I. Vayas, Full-scale tests on used steel storage racks, Steel Construction 12 (2019) 231-242. URL: 
https://onlinelibrary.wiley.com/doi/abs/10.1002/stco.201900009. doi:10.1002/stco.201900009.

[45] V. Kilar, S. Petrovcic, D. Koren, S. Silih, Seismic analysis of an asymmetric fixed base and base-isolated high-rack steel structure, Engineering structures 33 (2011) 3471-3482.

[46] V. Kilar, S. Petrovcic, D. Koren, S. Silih, Cost viability of a base isolation system for the seismic protection of a steel high-rack structure, International Journal of Steel Structures 13 (2013) 253-263.

[47] CEB-FIB, Seismic design of precast concrete building structures, State-of-art report prepared by Task Group 7.3, Fib, 2003.

[48] SAP2000 v.12, Csi software, [ONLINE] Available at: https ://www.csiamerica.com/, 2012.

[49] J. Marrow, The seismic vulnerability of the california wine industry - an experimental assessment, Structural Engineer's Association of California Annual Convention, Santa Barbara, CA, 2002, pp. 21-40.

[50] D. Dizhur, G. Simkin, M. Giaretton, G. Loporcaro, A. Palermo, J. Ingham, Performance of winery facilities during the 14 november 2016 kaikoura earthquake, Bulletin of the New Zealand Society for Earthquake Engineering 50 (2017) 206-224. doi:10.5459/bnzsee.50.2. $206-224$.

[51] E. C. Fischer, J. Liu, A. H. Varma, Investigation of cylindrical steel tank damage at wineries during earthquakes: Lessons learned and mitigation opportunities, Practice Periodical on Structural Design and Construction 21 (2016) 04016004. doi:10.1061/(ASCE) SC .1943-5576. 0000283. arXiv:https://ascelibrary.org/doi/pdf/10.1061/\%28ASCE\%29SC. 1943-5576.0000283.

[52] G. Candia, J. C. de la Llera, J. L. Almazán, A physical model for dynamic analysis of wine barrel stacks, Earthquake Engineering \& Structural Dynamics 39 (2010) 1063-1081. URL: https://onlinelibrary.wiley.com/doi/abs/10.1002/eqe.979. doi:10.1002/ eqe.979. arXiv:https://onlinelibrary.wiley.com/doi/pdf/10.1002/eqe.979.

[53] C. Chadwell, J. Stanley, M. J.M., Nonlinear analytical modeling and system verification of a wine barrel on a portable steel rack subject to seismic excitation, $8^{\text {th }}$ National Conference of Earthquake Engineering, San Francisco, California, 2006

[54] C. Chadwell, K. Brennan, M. Porter, Seismic isolation of wine barrel stacks on portable steel racks, WCEE $14^{\text {th }}$ World Conference on Earthquake Engineering, Beijing, China, 2008.

[55] R. Michael, Design and development of a seismic isolation system for commercial storage rack, 2013. [Retrieved from https://etd.ohiolink.edu/]. (Electronic Thesis or Dissertation).

[56] M. Ferrari, Lokibase: the device for seismic isolation of pallet racking systems, Costruzioni Metalliche 3 (2019) 82-91.

[57] M. Ferrari, Lokibase: the device for seismic isolation of pallet racking systems, Costruzioni Metalliche 4 (2019) 111-122.

[58] FIP Industriale, SCatalogue S04 - Curved Surface Sliders, Padova, Italy. Available on-line at http://www.fipindustriale.it, 2013.

[59] V. Piluso, R. Montuori, E. Nastri, A. Paciello, Seismic response of mrf-cbf dual systems equipped with low damage friction connections, Journal of Constructional Steel Research 154 (2019) 263 - 277. URL: http://www.sciencedirect.com/science/article/ pii/S0143974X18306291. doi:https://doi.org/10.1016/j.jcsr.2018.12.008.

[60] E. Nastri, M. D’Aniello, M. Zimbru, S. Streppone, R. Landolfo, R. Montuori, V. Piluso, Seismic response of steel moment resisting frames equipped with friction beam-to-column joints, Soil Dynamics and Earthquake Engineering 119 (2019) 144 - 157. URL: http://www. sciencedirect.com/science/article/pii/S0267726118304986. doi:https://doi.org/10.1016/j.soildyn.2019.01.009.

[61] M. Latour, G. Rizzano, A. Santiago, L. S. da Silva, Experimental response of a low-yielding, self-centering, rocking column base joint with friction dampers, Soil Dynamics and Earthquake Engineering 116 (2019) 580 - 592. URL: http://www. sciencedirect.com/science/ article/pii/S0267726118305074. doi:https://doi.org/10.1016/j.soildyn.2018.10.011.

[62] Z. Tang, G. Clifton, J. Lim, J. Maguire, L. Teh, Increasing seismic resilience of pallet racking systems using sliding friction baseplates, 2017 NZSEE conference, New Zeland, 2017.

[63] G. Clifton, Semi-rigid joints for moment resisting steel framed seismic-resisting systems (2005).

[64] A. Freitas, F. Souza, M. Freitas, Analysis and behavior of steel storage drive-in racks, Thin-walled structures 48 (2010) $110-117$. 
[65] M. Shaheen, K. Rasmussen, Seismic tests of drive-in steel storage racks in cross-aisle direction, Journal of constructional steel research 162 (2019) 1-18.

[66] M. Shaheen, K. Rasmussen, Design methods of drive-in steel storage racks, $8^{\text {th }}$ Eurosteel2017, Copenhagen, Denmark, 2017.

[67] M. Mucciarelli, D. Liberatore, Guest editorial: The emilia 2012 earthquakes, italy, Bulletin of Earthquake Engineering 12 (2014) 2111-2116. URL: https://doi.org/10.1007/s10518-014-9629-6. doi:10.1007/s10518-014-9629-6.

[68] F. Saitta, G. Bongiovanni, G. Buffarini, P. Clemente, A. Martelli, A. Marzo, G. Marghella, M. Indirli, A. Poggianti, Behaviour of industrial buildings in the pianura padana emiliana earthquake, Energia Ambiente Innovazione 4/5 (2012) 47-57.

[69] D. A. Bournas, P. Negro, F. F. Taucer, Performance of industrial buildings during the emilia earthquakes in northern italy and recommendations for their strengthening, Bulletin of Earthquake Engineering 12 (2014) 2383-2404. URL: https://doi.org/10.1007/ s10518-013-9466-z. doi:10.1007/s10518-013-9466-z.

[70] A. Franco, S. Massimiani, G. Royer-Carfagni, Passive control of steel storage racks for parmigiano reggiano cheese under seismic accelerations, Journal of earthquake engineering 19 (2015) 1222-1259.

[71] T. Takeuchi, K. Suzuki, Performance-based design for truss-frame structures using dissipation devices, $4^{\text {th }}$ International speciality conference, Naples, Italy, 2003. 